R\&D Project Report

\title{
3DCG reconstitution and virtual reality of UNESCO world heritage in danger: the Citadel of Bam
}

\author{
Kinji ONO ${ }^{1}$, Elham ANDAROODI ${ }^{2}$, Alireza EINIFAR ${ }^{3}$, Nobuaki $\mathrm{ABE}^{4}$, Moham- \\ mad Reza MATINI ${ }^{5}$, Olivier BOUET ${ }^{6}$, Frank $\mathrm{CHOPIN}^{7}$, Takashi KAWAI ${ }^{8}$, Asanobu \\ KITAMOTO $^{9}$, Asaka ITO ${ }^{10}$, Eskandar MOKHTARI ${ }^{11}$, Saeed EINIFAR ${ }^{12}$, Seyyed \\ Mohammad BEHESHTI ${ }^{13}$, and Chahryar ADLE ${ }^{14}$ \\ ${ }^{1,2,5,9}$ National Institute of Informatics, ${ }^{3}$ University of Tehran, ${ }^{4,8}$ Waseda University, \\ 6,7 'ecole Nationale Superieure d'Architecture Paris Val de Seine (ENSAPVS), Vir- \\ tual Space of Conception in Architecture and Urbanism (EVCAU), ${ }^{11,13}$ Iranian Cultural \\ Heritage and Tourism Organization, ${ }^{12}$ Raazaahang Architectural Firm, ${ }^{10}$ Ergovisions, \\ ${ }^{14}$ Centre Nationale de Recherche Scientifique
}

\begin{abstract}
This paper provides a report of a research project on virtual revival of the Citadel of Bam, a UNESCO world heritage site in danger that was destroyed in an earthquake in 2003. The simulation of damaged buildings that lies along the primary axes of the citadel and 3-D reconstitution using state-of-the-art 3DCG tools are presented. The key approach to 3-D modeling of the destroyed buildings is complementary usage of heterogeneous data such as 2-D maps, photos, cartography maps, and sketches in collaboration between different teams. As the basic 2-D maps had error, analytic and comparative research is conducted on diverse data resources to create a knowledge-base for the 3DCG restoration of the site. The process of modeling is completed with regard to the complicated and curved mud brick buildings with traditional architectural details. For this purpose proper functions of the tools is selected and in some cases different tools are used. The modeling is done by linking the component with their semantic by a metadata-based layer naming process. The tasks of evaluating the historical, architectural, and technical details of the 3-D buildings are done in parallel with the modeling by a team of CG and architecture experts in order to increase the precision of the 3DCG reconstitution so that it can be used as a reference for the physical restoration. The first trial version of virtual reality demonstration of the main axes of the Citadel of Bam is described. The paper concludes with proposals to enhance the process of simulation and also to open the restricted views of the virtual reconstitution on Internet.
\end{abstract}

\section{KEYWORDS}

3DCG, virtual reconstitution, Citadel of Bam, 3-D modeling, heterogeneous data, semantic layer management, modeling technical evaluation, virtual reality demonstration

\footnotetext{
Received August 10, 2007; Revised November 27, 2007; Accepted January 8 , 2008.

1) ono@nii.ac.jp, ${ }^{2)}$ elham@nii.ac.jp, ${ }^{3)}$ aeinifar@ut.ac.ir,

4) zen@toki.waseda.jp, ${ }^{5}$ matini@nii.ac.jp,

${ }^{6)}$ olivier.bouet@paris-valdeseine.archi.fr, ${ }^{7)}$ lfchopin@club-internet.fr,

${ }^{8)}$ MXE03620@nifty.com, ${ }^{9)}$ kitamoto@nii.ac.jp.

${ }^{10)}$ asaka_ito@ergovisions.com, ${ }^{11)}$ eskandarmokhtari@yahoo.com,

DOI: $10.2201 / \mathrm{NiiPi} .2008 .5 .10$
}

12)info@razahang.com, ${ }^{14)}$ cadle1944@yahoo.com 


\section{Introduction}

The historical city of Bam is situated along the Silk Road more than 1200 kilometers south of Tehran, and it once flourished for its production of silk and cotton. The city is well known by its qanat water management system $^{1)}$, mud brick citadel, and date palm trees. An earthquake measuring 6.3 on the Richter scale occurred at Friday 26 December 2003 and destroyed many of its quarters. The historical Citadel of Bam (Arg-e-Bam) was destroyed, and many lives were lost. Restoration and reconstruction of the citadel, which is now classed as a world heritage site in danger ${ }^{2}$, will be a great challenge and many organizations and individuals are attempting to find adequate solutions ${ }^{3)}$.

As part of the Digital Silk Roads project a threedimensional reconstitution and virtual reality of the Citadel of Bam was proposed. Revival of this heritage in the virtual world seems essential because of the complexity of physical reconstruction. Any physical restoration might face limitations of technique, material, manpower, budget, and even access to the site ${ }^{4)}$. Our 3-D reconstitution and virtual reality demonstration are parts of the virtual revival of the Citadel of Bam. Our research activity was motivated upon the following reasons:

- A virtual reconstitution is faster and less expensive than a physical one.

- A revival in the virtual world may be the only solution for those spaces which are very difficult or impossible to reconstruct.

- A systematic knowledge base can be provided of raw documents such as photos, maps, movies, texts, etc., to build three-dimensional models and identify the shortcomings of data and documentation of the site.

- The 3-D models would be important references for physical reconstruction.

\footnotetext{
1) A qanat is a water management system used to provide a reliable supply of water to human settlements or for irrigation in hot arid and semiarid climates. The technology is known to have developed in ancient Persia, and then spread to other cultures, especially along the Silk Road (from http://en.wikipedia.org/wiki/Qanat [7 Jan, 2008]). The geographical location of Bam city has helped to sustain its advanced qanat system for thousands of years (possibly since the Achaemenian dynasty in 500 B.C.).

2) http://whc.unesco.org/en/list/1208 [7 Jan, 2008].

3) The rehabilitation of the citadel has been a topic of intensive discussion. In particular, on 17-21 April 2004, an international workshop took place in Bam. Some 52 senior representatives and experts from different organizations and universities around the world shared experiences and lessons taken from the earthquake and proposed a list of recommendations that was published as the Bam declaration (from www.international.icomos.org/xian2005/Bamdeclaration.pdf [7 Jan, 2008]).

4) The upper part of the citadel presents a complex problem regarding debris removal and stabilization; it is a critical situation hampering access and field operations.
}

- A virtual reality of the citadel can be viewed and demonstrated remotely.

After the disaster, we started to make a 3-D simulation of the destroyed buildings inside the citadel by using state-of-the-art computer graphics tools and prepare a virtual reality demonstration of the digitally reconstituted buildings.

\subsection{First phase of research}

The Citadel of Bam covers a huge area and has several complexes. To start 3-D modeling, we had to select a number of target cases. We referred to the site plan and specified two important axes, north-south and eastwest. The north-south axis runs from the main entrance gate and ascends to the governor's section and highest point of the citadel. Major public buildings are located along this axis. The east-west axis runs from the bazaar and passes through the religious and educational buildings and noble houses before reaching the ancient east gate. We selected these two axes for the first phase of 3-D modeling.

\subsection{Summary of the research process}

The steps of the project are outlined in Fig. 1 and are summarized as follows:

- Collect data including photos, maps, videos and documents related to Bam from diverse and sparse resources.

- Conduct analytic and comparative research on this heterogeneous data, as well as categorization and annotation to complete the basic resources for modeling.

- Develop a three-dimensional simulation of buildings inside the citadel by complementary application of diverse data resources by using state-ofthe-art 3-D modeling techniques and tools.

- Add semantic information to the 3-D models through a systematic modeling process.

- Devise a virtual reality demonstration of the simulated spaces by importing a VRML ${ }^{5)}$ file of the 3$\mathrm{D}$ models into VR tools and set up a virtual walkthrough of the digitally restored buildings.

This paper is a report on the current state of the project. A brief history of the citadel and its situation after the

5) VRML stands for Virtual Reality Modeling Language or Virtual Reality Markup Language. It is a text file format in which vertices and edges for a 3D polygon can be specified along with the surface color, image-mapped textures, shininess, transparency, and so on. (from http://encyclopedia.thefreedictionary.com/VRML [7 Jan, 2008]). 


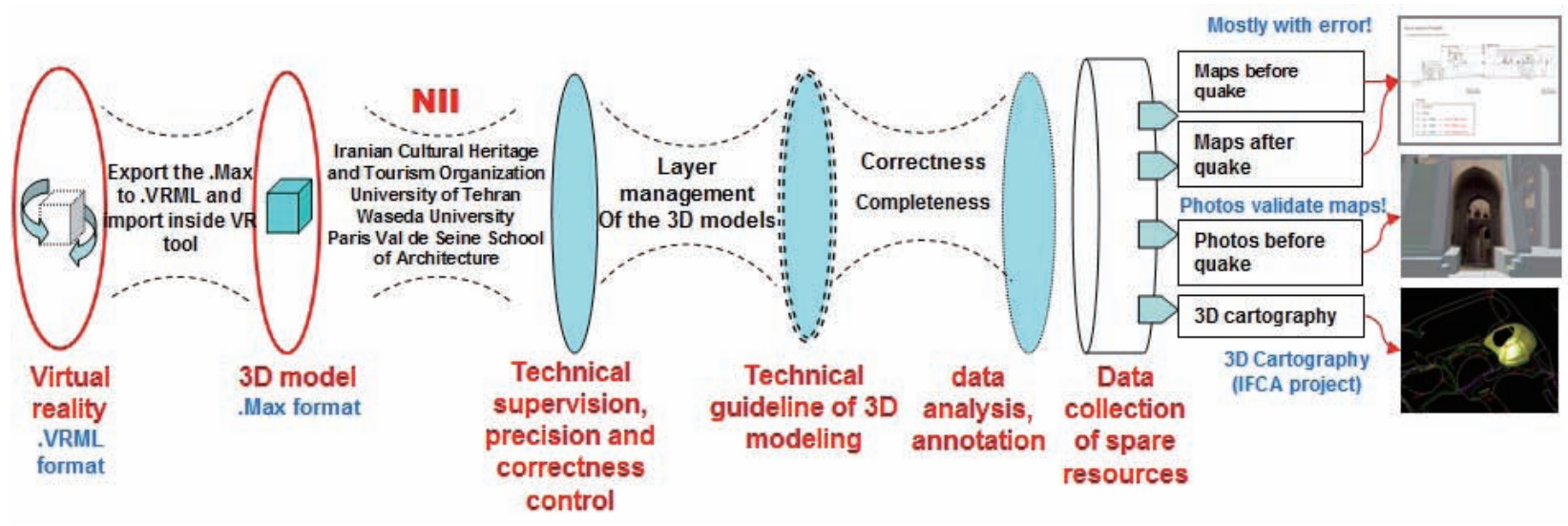

Fig. 1 Process of virtual reconstitution of the Citadel of Bam.

earthquake is explained in section 2. The process of 3$\mathrm{D}$ modeling is described in section 3. Semantic annotation of the data and the provision of technical guidelines are covered in sections 4 and 5. Sections 6, 7, and 8 describe the first phase of 3-D modeling of the major case studies inside the citadel. Technical evaluation and modification of the 3-D models are discussed in section 9. The virtual reality demonstration of the simulated buildings is introduced in section 10. The paper concludes with future perspectives in section 11 .

\section{Historical and architectural back- ground}

Old Bam was one of five areas of the state of Pars. Its strategic location along roads connecting the Silk roads from Afghanistan and India to the centre to Ray (present-day Tehran) and toward the east to Merv and toward the west to Istanbul made it an important historical and commercial location in the south-eastern Persia from about 120 B.C. (Fig. 2). Caravans that passed through Bam carried spice and silk and cotton clothes. The travelogues of people who visited Bam between the 9th to 11th centuries mentioned the extremely fine cotton and silk cloth that used to be produced there and exported to the major cities along the Silk Road [1]-[3].

The historical Citadel of Bam covers approximately $200000 \mathrm{~m}^{2}$. It is one of the biggest mud brick defensive complexes in the world and has had around 20 centuries of habitation, making it one of the most ancient earthen structures (Fig. 3). Its strategic location on top of a hill about 50 meters above the surrounding terrain gave it an important defensive function and made it easy to fortify.

The citadel is a typical desert city divided into eight residential districts and a governor's section. The city is surrounded by a defensive wall more than 1500 meters long and 5 to 6 meters in height and is protected by 38 watch towers and a moat all around it. The main gate controlled the comings and goings of inhabitants and travellers. Right past the gate, there is a linear bazaar passing through the residential districts. Around 20 building types existed before the quake as complete examples of a typical Middle Eastern desert city made from layers of mud. The residential district includes mosque, bazaar, tekkiyeh (religious plaza or theatre), caravanserai, school, bath, zoorkhaneh (a place for playing traditional sports) and houses of noblemen. The governor's section consists of defensive complexes such as stable, barracks, mill, and commander's house. The governor's quarters consists of the governor's house, bath, watch tower, and the Chaharfasl (Four Season) reception room at the top of the citadel. Variety of function of buildings inside the citadel made it as a precious example for desert city typology along the Silk Road.

Although there are different hypotheses as to the founding date of this citadel, i.e., some time during the Achaemenian and Partian dynasties (550 B.C.-224 A.D), most of the buildings that existed before the earthquake seemed to belong to the Teimorid to Qajar period (1381-1921). [1]-[3] Table 1 lists a historical chronology of the citadel and shows photos of remains corresponding to the respective historical periods.

Some huge mud brick structures like the Great Iwan $^{6)}$ of the Jamee mosque might date from the Samanid dynasty and Seljuk dynasty (819-1186). Travelogues from these periods mention the Citadel of Bam and this mosque in their records (e.g., Ibne-Haugal (943-977) [4]. The Citadel of Bam was evacuated dur-

\footnotetext{
6) Large vaulted halls having one side open to a court; prevalent in Parthian, Sassanian, and Islamic architecture: http://www.getty.edu/vow/ AATFullDisplay?find $=i w a n \& \operatorname{logic}=A N D \&$ note $=\&$ english $=N \& p r e v \_p a g e=1 \&$ subjectid $=300075830$ [7 Jan, 2008]
} 
Table 1 Chronology of the Citadel of Bam and comparative analysis of remains from different centuries.

\begin{tabular}{|c|c|c|}
\hline date & Location of remains & Sample of remains \\
\hline $\begin{array}{l}550 \\
\text { B.C.- } \\
224 \text { A }\end{array}$ & $\begin{array}{l}\text { The remains consist of large mud bricks that formed arches } \\
\text { or walls at the top of a cliff. Their original function is un- } \\
\text { clear. Was it a citadel or was it a temple? }\end{array}$ & Mud-brick arch discovered after quake. \\
\hline $\begin{array}{l}819- \\
1186 \\
\text { A.D. }\end{array}$ & $\begin{array}{l}\text { The remains consist of the old gate or parts of walls in the } \\
\text { governor's district, especially around the mosque. The site } \\
\text { is cited in famous travelogues to be a huge citadel. How- } \\
\text { ever, it seems to be the noblemen district of a bigger citadel. } \\
\text { It is known that the region flourished with the production } \\
\text { of silk and cotton cloth. }\end{array}$ & $\begin{array}{l}\text { Main mud-brick iwan of the mosque (photo credit: } \\
\text { ICHTO). }\end{array}$ \\
\hline $\begin{array}{l}1381- \\
1921 \\
\text { A.D. }\end{array}$ & $\begin{array}{l}\text { Constructions belonging to different periods. Over the } \\
\text { course of centuries of economic stagnancy in the region, } \\
\text { people's dwellings moved closer to the center and the older } \\
\text { citadel shrank to its current size. }\end{array}$ & $\begin{array}{l}\text { The governor's district and eight other residential districts } \\
\text { in the Citadel of Bam with different types of public build- } \\
\text { ings, including a mosque, school, bath, bazaar, sports hall, } \\
\text { and religious theater }\end{array}$ \\
\hline
\end{tabular}




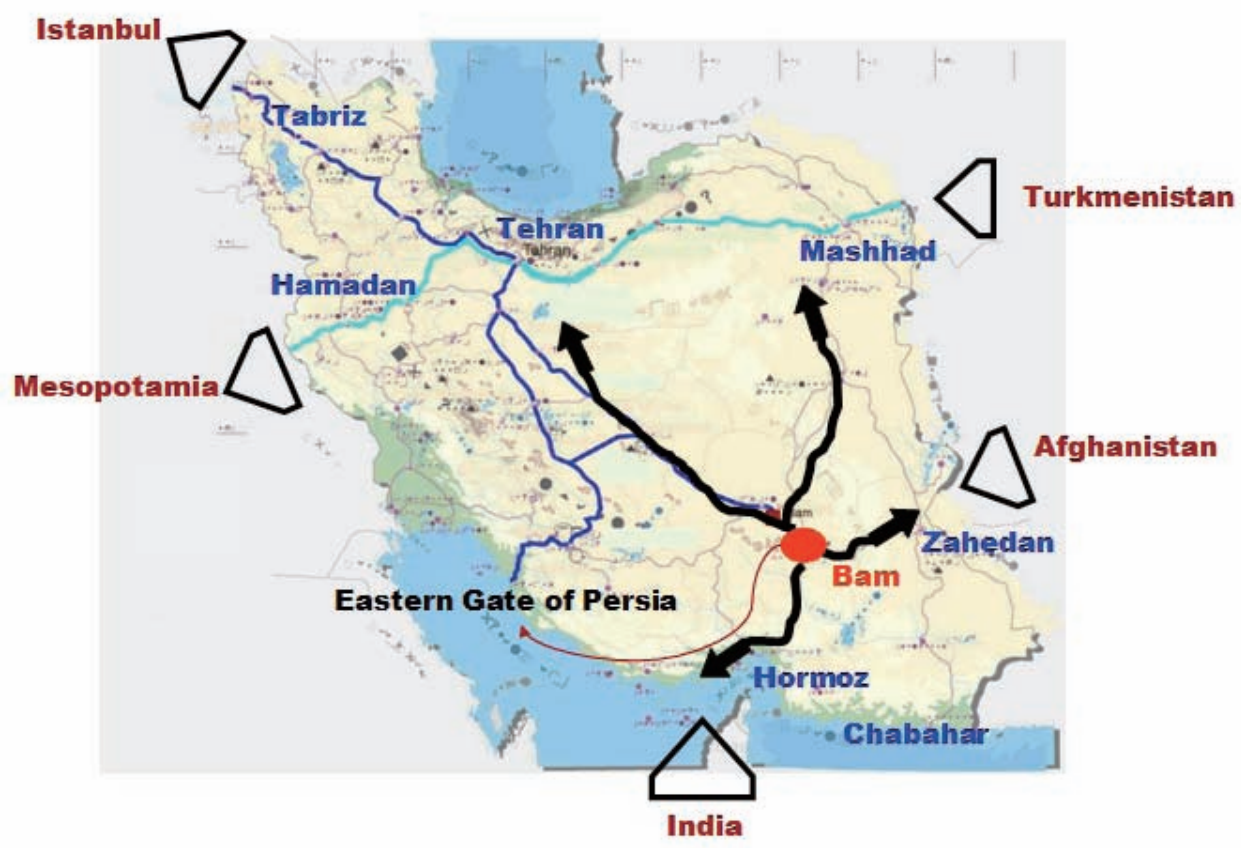

Fig. 2 Strategic location of Bam along the Silk and Spice Roads.

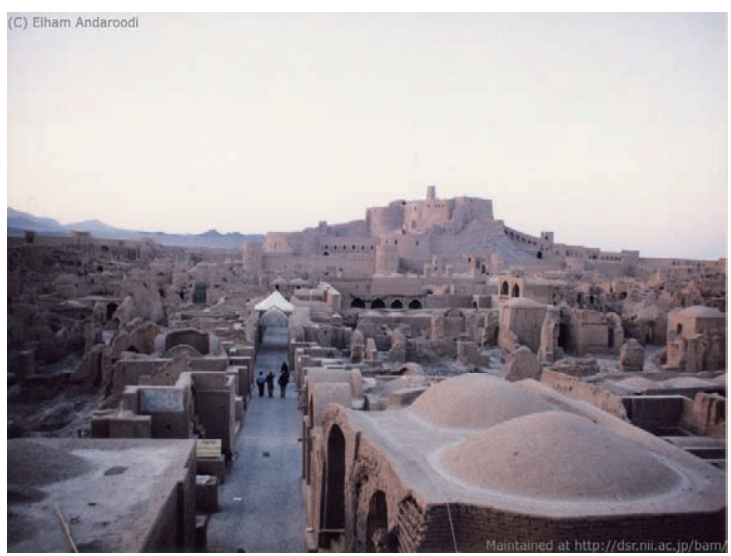

Fig. 3 The Citadel of Bam: a view from the first city wall toward the bazaar, governor's district, and main tower.

ing the Qajar Period ${ }^{7}$.

The material used to build the citadel is sticky mud containing a very resistant type of clay for building good-quality sun dried brick [1]. The region is very dry and there are only a few rainy days during the year; this had helped the mud brick constructions to last a long

\footnotetext{
7) For further information about the history Citadel of Bam, please refer to the complete list of references from the ICHTO Documentation Center: http://www.ichodoc.ir/argebam/bookname.htm [7 Jan, 2008].
}

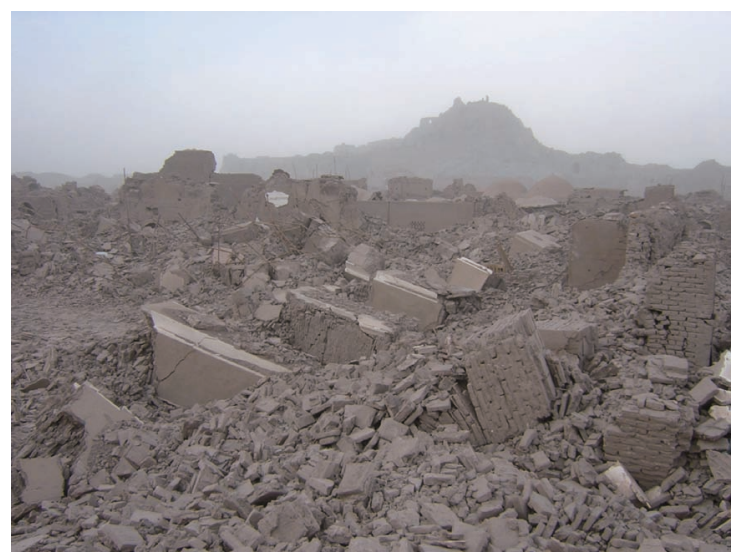

Fig. 4 The Citadel of Bam: the same view as Fig. 3 after the earthquake in December 2003.

time.

Following the destruction caused by the earthquake, UNESCO added "Bam and its Cultural Landscape" to its World Heritage in Danger list in 2004 (UNESCO World Heritage Centre ${ }^{8)}$ ). Although the earthquake, as can be seen from Fig. 4, almost completely destroyed the site, it led to new archaeological discoveries. It was

${ }^{8)}$ http://whc.unesco.org/en/list/1208 [7 Jan, 2008] 


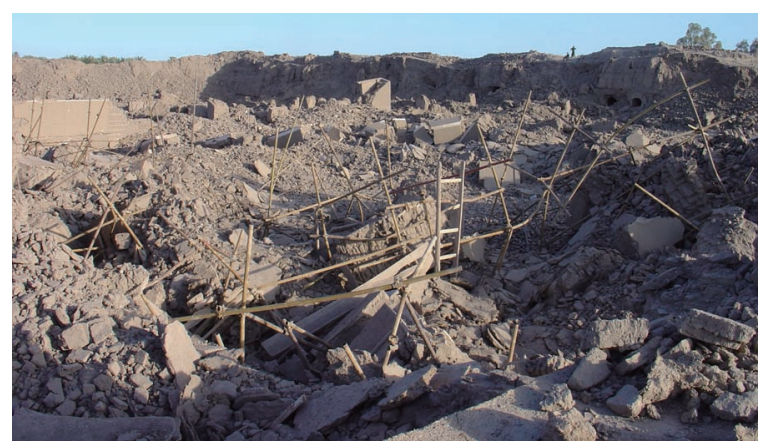

Fig. 5 Mosque after the earthquake.

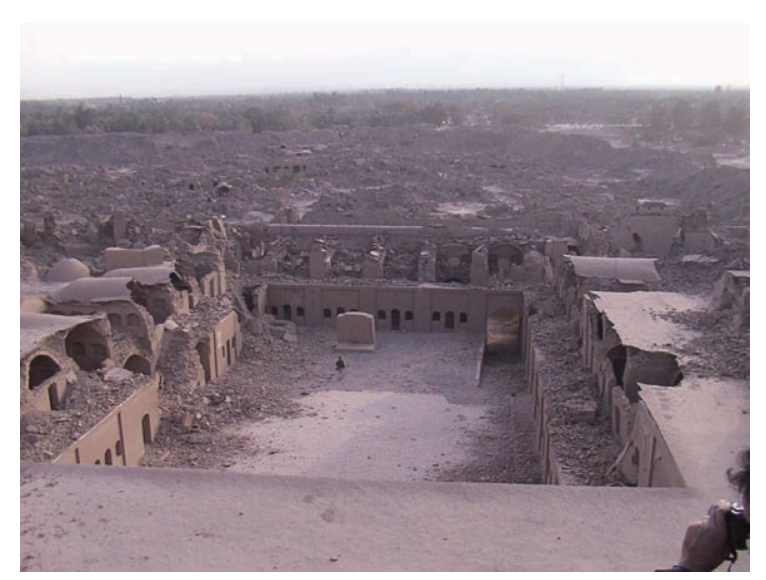

Fig. 6 Barrack after the earthquake.

as if the destruction had peeled back layers of newer mud brick to reveal ancient ones underneath. Very old mud brick constructions were revealed in the upper part of the citadel, and their huge size was reminiscent of ancient mud brick sites such as ancient Tchogha Zanbil $^{9)}$ [1] (see Table 1).

The earthquake also offered an opportunity to study the architectural styles of mud brick structures. Parts of the citadel, e.g., the stables and barrack (Fig. 6), were not as seriously damaged as the rest, and the earthquake revealed the construction of vaults and the roof that had been hidden in the finished buildings. Learning the manner in which such structures withstand an earthquake and discovering why some parts remained standing while other parts were demolished can give us important information about how such structures weather natural disasters.

\footnotetext{
9) Tchogha Zanbil is a UNESCO world heritage site containing the ruins of the holy city of the Kingdom of Elam, surrounded by three huge concentric walls. Founded c. 1250 B.C., the city remained unfinished after it was invaded by Ashurbanipal, as shown by the thousands of unused bricks left at the site: http://whc.unesco.org/pg.cfm?cid=31\&id_site=113 [7 Jan, 2008]).
}

Before the earthquake, the citadel has been restored several times. The last restoration started around 35 years ago and continued until 2003. Many parts of the citadel (like the bazaar) were reconstructed during the restoration period. The situation of the citadel just before the earthquake was a reference for our 3-D reconstitution.

\section{3DCG of Citadel of Bam}

\subsection{Review of the state of the art}

There are several examples of 3-D modeling of a cultural heritage or of damaged sites by using photogrammetry, photo modeling, and other 3-D modeling techniques. An example of a virtual heritage is the reconstitution of the Bamian Great Buddha that was generated with VirtuoZo digital photogrammetric systems [5]. Another example is the virtual reconstitution of the Great Buddha in Japan, which uses geometric modeling (scanning, merging, and alignment of the target object) and photometric and environmental modeling for rendering and demonstration [6].

Regarding virtual representations of individual buildings, the Parthenon virtual reality [7] was modeled using laser scanning and photogrammetry. Another example is the virtual reality of the city of Pompei [8] wherein 3-D models of the target buildings were created from available documents.

In contrast to the cases described above, our target buildings had mostly been destroyed. Furthermore, 3-D simulation was necessary for the interior as well as the exterior spaces of buildings that were made from mud brick and had unusual curves, arches, and other complicated shapes. Moreover, the site is huge (about 200,000 $\mathrm{m}^{2}$ ) and comprises several districts. There are few detailed images of the buildings that are good enough for reconstitution by photogrammetry technique [9], [10]. Therefore, we chose the method of 3-D modeling from 2-D maps and other complementary resources.

\subsection{Process of 3-D modeling}

Modeling of a building involves making the geometry of the building components in three dimensions by using 3-D modeling software such as AutoCAD ${ }^{\circledR 10)}$ and MAX ${ }^{\circledR 11)}$ [11], [12]. The basic data corresponds

\footnotetext{
10) AutoCAD ${ }^{\circledR}$ is a suite of Computer Aided Design (CAD) software products for 2- and 3-Dimensional design and drafting, developed and sold by Autodesk, Inc. (from http://usa.autodesk.com/adsk/servlet/ index?siteID $=123112 \&$ id $=2704278$ [7 Jan, 2008].

11) $3 \mathrm{D}$ Studio Max (sometimes called MAX ${ }^{\circledR}$ or just MAX) is a 3-Dimensional vector graphics and animation program, written by Autodesk Media \& Entertainment (formerly known as Discreet and Kinetix). It was developed as a successor to 3D Studio for DOS, but for the Win32 platform. Kinetix was later merged with Autodesk's latest acquisition, Discreet Logic. (from http://usa.autodesk.com/adsk/servlet/index $?$ id= $=5659302 \&$ siteID=123112 [7
} 
to the dimensions of the building. If the basic data is accurate, the model will accurately simulate the real building. If it has error, the modeling process will face complexity in order to solve the errors by using other data such as photos.

The demolition of the site, lack of precise 2-D maps and lack of photos before the earthquake has made the process of 3-D modeling of this project a rigorous research activity by collaboration of experts of history or architecture and computer graphics who supervised the 3-D modelers. The research activity that supported the modeling task has ensured the precise virtual reconstitution of the damaged heritage on the contrary of errors of 2-D maps and lack of photos. The modeling of first phase of the project proceeded as follows.

\section{Provision of primary data}

The basic data consisted of 2-D maps, photos, movies or textual explanations, aerial photos, cartography maps, oral explanations and other pieces of information related to Bam found in different references (see section 4).

\section{Development of 3-D modeling guidelines}

Guidelines for drawing and developing the 3-D models were created so that different modelers could coordinate their work, to provide coherent output and reduce the errors in the final model.

\section{3-D modeling}

The development of the 3-D models from the different case studies was collaboration between researchers and 3-D modelers. The first step was to superimpose 2D maps on the 3-D cartography data (IFCA project) to compensate for the errors in the maps. Photos, movies and sketches were used to modify the model, especially the elevations and interiors. The team exploited stateof-the-art modeling tools, but as a unified 3DCG tool for simulation of architectural buildings could not be found, the team had to use different tools simultaneously.

The three groups of modelers had to conduct tasks jointly in different stages of this project (see sections 6,7 and 8 ). It is important to notice their different approaches even though they used the same tools.

\section{3-D model technical quality and correctness control}

This task was part of the comparative study of 3D models and heterogeneous data sources, and it increased the precision and correctness of the final 3-D models by identifying the architectural, historical or technical modeling errors. Because of the various re-

Jan, 2008]. sources and errors of the 2-D maps, this process was essential to ensure the precision and quality of the models and to notify the modelers of their errors.

\section{Management and coordination of different teams}

The first phase of the virtual reconstitution involved groups from the National Institute of Informatics (NII) and Waseda University in Japan and the Iranian Cultural Heritage and Tourism Organization (ICHTO). The first 3-D reconstitution of the main entrance and bazaar began in October, 2004 by team of University of Waseda. The University of Tehran joined the project in September 2005 and conducted a survey of buildings the site for 3-D modeling of five case studies. Espace Virtuel de Conception Architecturale et Urbaine (EVCAU), a laboratory of the Ecole Nationale Supérieure d'Architecture de Paris-Val de Seine (ENSA PVS) in France, joined the project in October 2006; they helped to improve the modeling skills of the group by simulating two case studies, the caravanserai and school inside the citadel.

The experience of managing modeling groups with different attitudes and capabilities provided important insights into how to produce a coherent output from such a large undertaking.

In the following of the paper each process is discussed in detail.

\section{Analytic management of heteroge- nious data for 3-D modeling}

The case studies selected for modeling had varying degrees of damage, from totally destroyed (as in the case of the mosque, Fig. 5) to less than half demolished (as in the case of the barracks, Fig. 6). Experts believed that the construction of mosque on older layers of habitation and on non-resistant soil and the construction of the barracks on a strong foundation rock were the reasons for their respective weakness and strength in the earthquake. In all cases, though, the amount of damage was considerable.

The inadequacies of the 2-D maps made collecting other information and annotating the data essential, the documents we worked with were resources with missing data. The images had only limited views of the complicated mud brick structures. This entailed a vast investigation to find pieces of information because the Citadel of Bam had not been completely documented before the quake. For this task, we had to be like architectural detectives on a quest to discover the ambiguous shapes of buildings that had disappeared.

\section{Data resources}

The basic data was acquired from the following sources and were implemented complementary for 3-D 

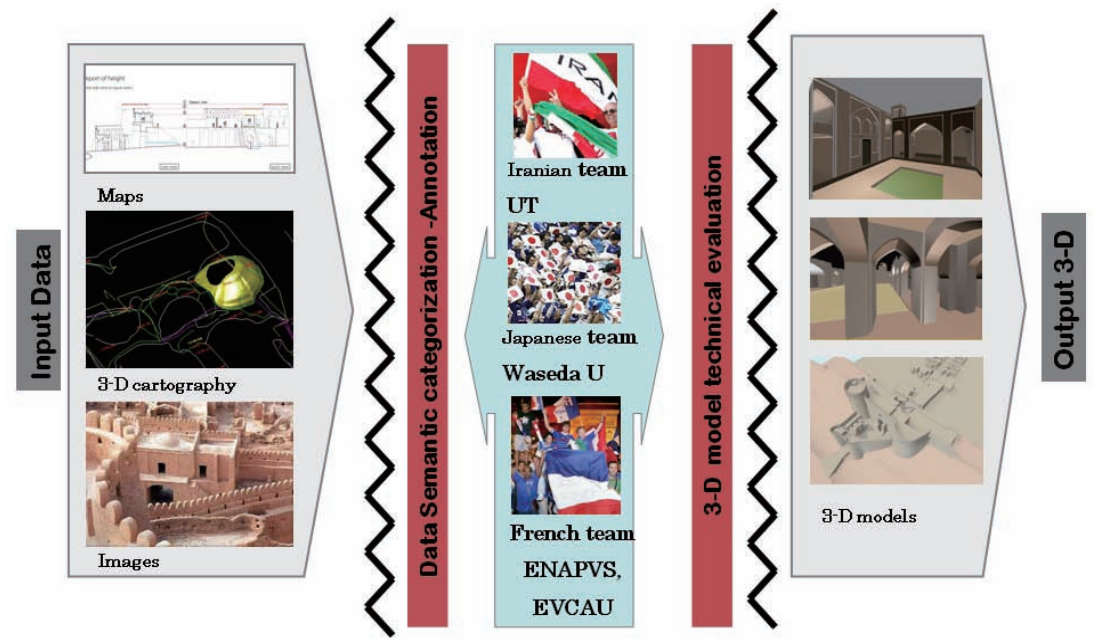

Fig. 7 Research process of data analysis and 3-D model evaluation.

modeling (Fig. 7):

- Iranian Cultural Heritage Organization (Bam recovery project office, Documentation Centre, etc.), for maps, photos, texts, movies, etc.,

- National Cartography Centre (of Iran), for aerial photos,

- IFCA (Irano-French Cartography Agreement) and Centre National de la Recherche Scientifique (CNRS), for a three-dimensional cartography map in the form of a $\mathrm{DWG}^{12)}$ file, ${ }^{13)}$

- Open source data from the Internet, for images ${ }^{14)}$, and the website of the DSR project, for a collection of images of the Citadel of Bam, ${ }^{15)}$

- Survey of information in the form of photos and maps showing details and perspectives of the site after the earthquake

- Verbal explanation made by experts who had worked at the site before the earthquake. ${ }^{16)}$

12) A file extension that indicates a drawing from the AutoCAD ${ }^{\circledR}$ Computer aided Design tool.

13) A project of Dr. Adle.

14) Here is a list of web pages for this purpose (last viewed on 1 November 2007): http://www.chnphoto.ir/

http://www.ichodoc.ir/argeBam/

http://www.cais-soas.com/CAIS/virtual_museum/parthian/Sites/Bam.htm

http://www.gimizu.de/orient/2001/kerman/Bam.html\#0911_d17

http://www.mcah.columbia.edu/Bam/main.htm

http://www.Bam-iran.com/Bam_City/index.htm

15) http://dsr.nii.ac.jp/Bam/collection/

16) Dr. Hossein Tayari (head of the Bam restoration project from 1995 to 2003),

Ms. Mahshid Jafarizadeh (Expert on the Bam restoration project).
4.1 Collected data and their role in modeling

Various data were used for developing the 3-D model as listed below.

\section{Maps}

There were maps and 2-D drawings of buildings from horizontal (plan) and vertical (façade, sections) plans from a survey done before the earthquake. These data were as follows:

- Underground floor plans

- Ground floor plans

- First floor plans

- Site plan

- Facades

- Sections

- Perspectives

The surveys had been done by the experts of the Bam restoration project before the earthquake, and they were of 23 buildings inside the citadel ${ }^{17)}$. Normally, a complete survey of a building includes different levels (from

\footnotetext{
17) The buildings are as follows:

Arg-e Bam (citadel) general map, main gate (south gate), governor's postal office, tea shop, west house of Saabaat, the religious theater (tekkiyeh), stable \& water storage, barracks, small house (west of the caravanserai), a house beside a passageway, Jaam'e mosque, governor's house, commander's mansion, Four Season building (Emarat Chahar Fassl), a house on the west side of the baazar, second gate (governor's district), complex governor's house, bazaar (inside the citadel), caravanserai (behind stable), school and school and houses of Mirza Naeem, and houses and complex of Mir.
} 

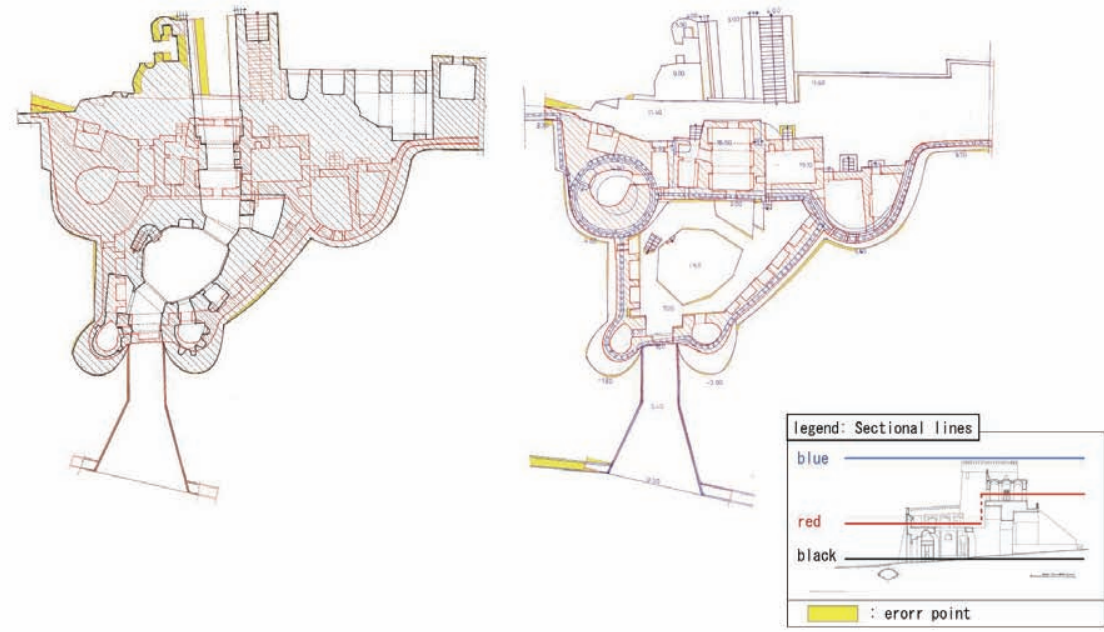

Fig. 8 Analysis of map of the main entrance and errors in coincidence between plans of different levels.

underground floors to the roof), complete sections, the outside and inside elevations (including the elevations of each space and each room), and details with all dimensions, and the scales range from 1:100 to even 1:1. However, due to limited sources for the survey and the complexity and huge scale of the site, our research had to deal with several shortcomings of these maps as follows:

- There are dimensional incompatibilities between the plans of different levels (Fig. 8 shows the case of the main gate (entrance)) and between plan and section.

- Elevation and sections are not provided for all facades of the building.

- There are errors in coincidence of the ground floor plan of the building and the roof plan derived from the 3-D cartography data (Fig. 9).

To cope with these shortcomings, we complemented the map data with the data listed below.

\section{3-D Cartography Map ${ }^{18)}$}

Cartography is defined as the study and making of maps from spatial information ${ }^{19)}$. The $3-D$ cartography map that we used as the reference was reconstituted from aerial photos of the Citadel of Bam from 1994. These photogrammetric materials were made available under the Irano-French 3-D Cartographic Agreement

${ }^{18)}$ This section is co authored by Dr. Chahryar Adle.

${ }^{19)}$ http://www.gtasa.asn.au/glossary/gloss_c.htm [7 Jan, 2008] on Bam (IFCA) and the Iranian National Cartographic Centre (NCC). The reconstitution provided by the 3-D cartography map is precise in relative value (comparison of the XYZ coordinate value of one element in the system with the XYZ coordinate value of another element in the system) to within $5 \mathrm{~cm}$ and in absolute terms within about a decimetre (for instance, regarding the $\mathrm{XYZ}$ of a point perhaps less than $10 \mathrm{~cm}$ in $\mathrm{X}$, less than $20 \mathrm{~cm}$ in $Y$ and less than $20 \mathrm{~cm}$ in $Z$ ). If any architectural or natural element is clicked on in the 3-D cartography map, the XYZ values in the $\mathrm{UTM}^{20)}$ system are revealed. The cartography map is developed by Micro Station ${ }^{\circledR}$ tool $^{21)}$ and imported as an AutoCAD ${ }^{\circledR}$ file with a DWG extension. Because of this, the colors of the layers of each set of lines have changed and become similar, and this complicates the layer management process. The map is a 'wire frame' 3-D model consisting of lines, not surfaces or solid volumes.

The cartography map was used as a reference for checking the correctness of plans surveyed before the earthquake (Fig. 9) and for the development of a 3-D model for free-hand constructed mud brick walls or vaulted roofs. Fig. 10 shows an example of the Great Iwan of the grand mosque. To develop such a model adjustment of lines of the map is necessary. In some cases like the tower of the main gate (see Fig. 11), the

\footnotetext{
20) Universal Transverse Mercator, a special grid map adopted by the National Imagery and Mapping Agency (NIMA). This grid is arranged so that the earth is divided into 60 north-south zones (each is a strip 6 degrees wide in longitude) These zones are numbered consecutively beginning with Zone 1 between 180 and 174 degrees west longitude.

www.seilerinst.com/gps/gpsterms.asp [7 Jan, 2008].

${ }^{21)}$ http://www.bentley.com/en-US/Products/MicroStation/ [7 Jan, 2008]
} 


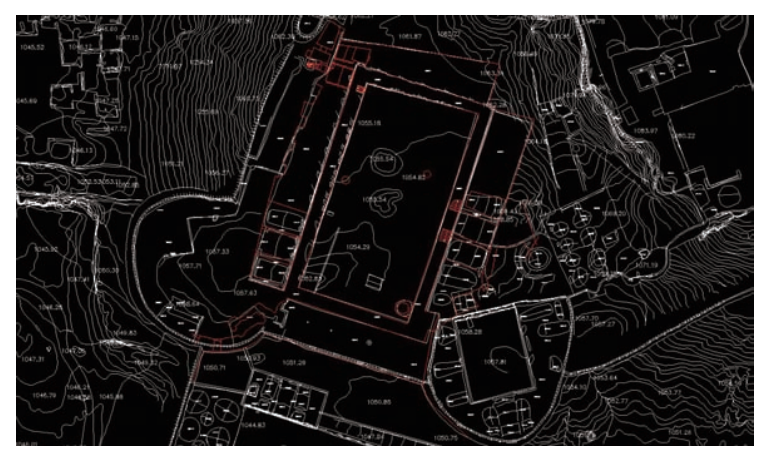

Fig. 9 Comparison of cartography map (white lines, IFCA project) and plan (red lines).

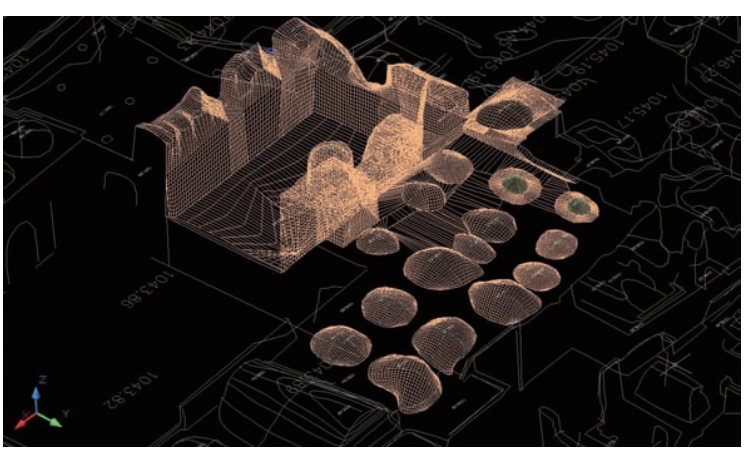

Fig. 10 Using 3-D cartography map (IFCA project) for development of the 3-D model of irregular and curved mud brick surfaces in the case study of the ancient iwan of the mosque.

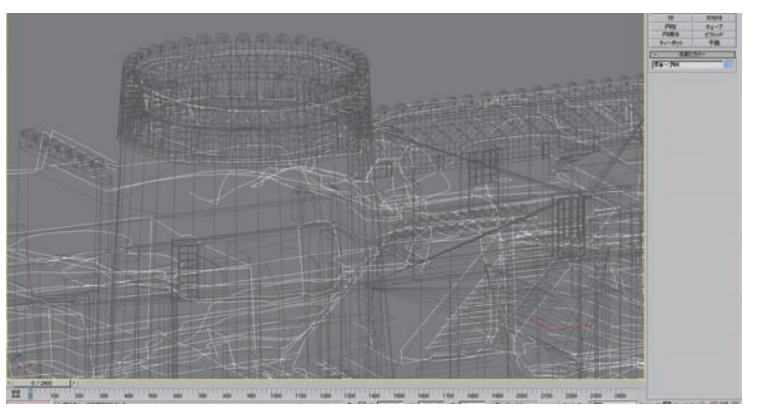

Fig. 11 Using cartography map (IFCA project) to modify the 3-D model of the tower of the citadel's main gate.

cartography map can resolve the problems stemming from dimension errors (including height errors). Sometimes, models long and narrow spaces like the bazaar can be adjusted by using the cartography map.

Although the 3-D wire frame model of the cartography map is the most reliable reference for checking the 3-D models, it has the following shortcomings:
- The map is drawn by hand and its lines need to be adjusted before they can be used for 3-D modeling.

- Although the shapes viewed from the top (roof plan), especially of the domes and vaults are precise, there is a serious lack of detail on the facades (vertical views).

- The errors in XYZ coordinates cause ambiguities in delicate forms requiring a precision of 30 centimetres or better.

\section{Photos}

The 2-D and 3-D cartography maps were used to model the walls and vaulted roofs. But these data sources didn't contain enough information for determining the frontage and elevations of the interior spaces. Hence, photos of the Citadel of Bam became the major complementary resource for the 3-D modeling.

We posted a call in three languages for contributions on the DSR website ${ }^{22)}$. We requested photos of the citadel, especially ones taken before the earthquake. As a result of this call, we collected more than 200 photos from website visitors of five nationalities (Fig. 12).

This photo collection has helped us to disambiguate the shapes of the facades, details, ornaments, and interiors. We also had access to or compiled photo databases from the following sources:

- Photos taken by individuals and sent to us by other means beside the DSR website,

- Photos taken by ICHTO during the restoration process,

- Photos taken at special events and ceremonies.

The collected photographs are of 37 spots $^{23)}$ around the citadel and were taken before the earthquake. Unfortunately, the photos still had a number of problems:

- Low resolution,

${ }^{22)}$ http://dsr.nii.ac.jp/bam/index.html.ja [7 Jan 2008]. The website was created by collaboration of Assoc. Prof. Dr. Asanobou Kitamoto and Dr. Elham Andaroodi.

23) General view, entry gate [main gate], southern wall, east of entry gate [east of the main gate], eastern wall, north-eastern wall, north-eastern wall behind the governor's mansion, external part of the north-eastern wall, northern wall, western wall, southern wall west of entry gate, bazaar, tekkiyeh, grand mosque, Mirza Naim school, Mirza Naim private residence, main caravanserai and Mir house, gymnasium (Zoorkhaneh), Al Rasoul mosque, baths, Jewish passageway, house located at the west side of the Jewish Passageway, small caravanserai, old wall, Konari neighborhood, stable, second entry gate, second wall, Kot E Kerm gate, third wall, barracks, commander's mansion, governor's mansion and watch tower, Four Seasons building (Emarat Chahar Fassl), governor's bath house and well, and tower 


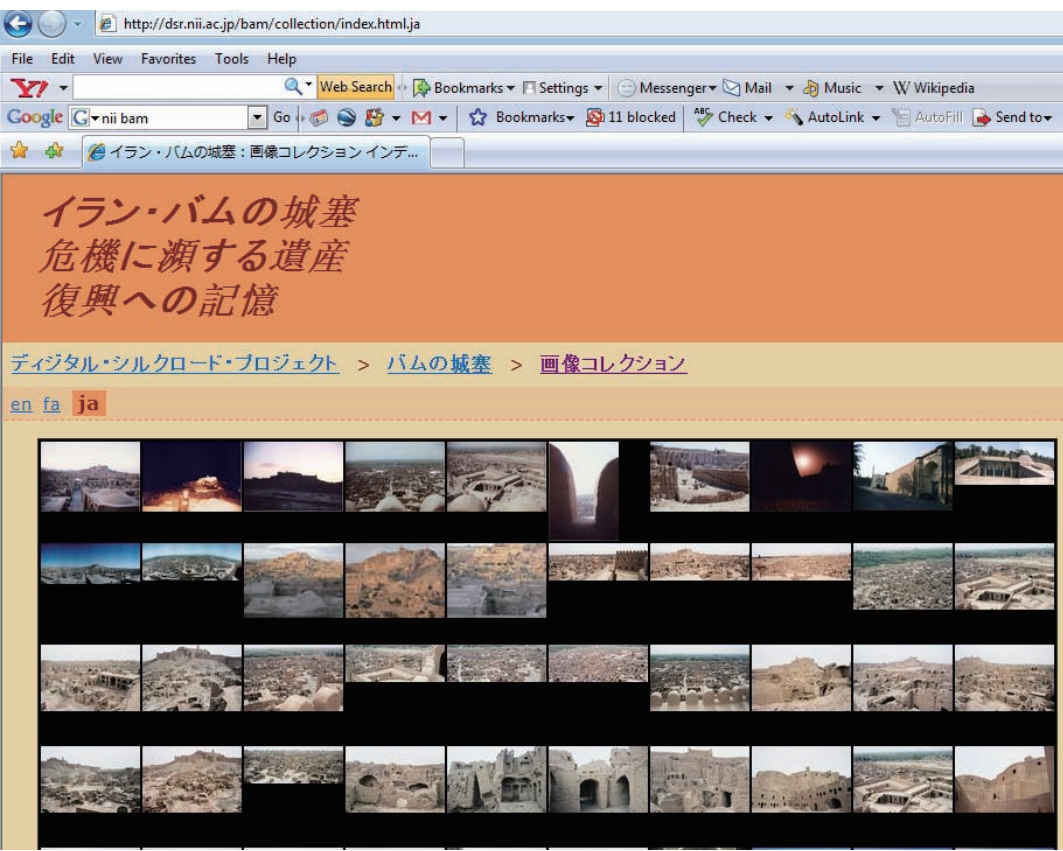

Fig. 12 Photo collection sent by contributor in response to open call for materials on the DSR website.

- Too many photos from popular views (such as Fig. 2) and very few images of private buildings or residential districts,

- Lack of images of interior spaces,

- No data related to settings of the cameras and no photos from calibrated cameras.

The demolished state of the buildings has made the process of photo archiving more complicated. Some information still exists and photos can still be taken of the remains that have been excavated. To complete the photo collection, we surveyed the site and photographed the two main axes after debris had been removed.

\section{Aerial Photos}

Aerial photographs of the Citadel of Bam taken on seven different years (the first dating from 50 years $\mathrm{ago}^{24)}$ ) and with a scale more than 1:2000 were provided by the National Cartography Centre and Digital Globe ${ }^{25)}$. These photos revealed the changing situation of the citadel during the last 50 years. In fact, we recognized three different periods as follows:

- Before 1971: the citadel was abandoned and suffered damage from nearby human habitation.

24) These years are 1335, 1343, 1356, 1360, 1373, 1375, and 1382 of the Persian calendar (2008 is $1386-1387$ of the Persian calendar)

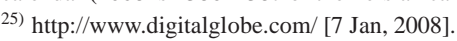

- From 1971 to 1993: the citadel was partially restored. (It was registered as the 154th national monument of Iran in 1966 and has been protected by the National Cultural Heritage Organization since 1971.)

- From 1993 to 2003: the citadel underwent massive reconstruction as one of five big ICHTO projects.

- 2003 and 2004: the citadel was destroyed in an earthquake and was covered by debris.

- After 2004: debris removal started and some buildings were excavated.

Aerial photos were complementary data for making the 3-D models. Although their scale is too small for them to be used to make a precise map, they were used when no other reference was available. Some of these photos are not perfectly vertical; hence, the facades, especially the east and north sides, are visible. In some cases like the west façade of the Mirza Naim School, no map or photo was available and aerial photos had to be used as the main reference for 3-D modeling.

\section{Movie, texts, and sketches}

Other references for completing the 3-D models were movies taken by professionals ${ }^{26}$ ) or by amateurs of

26) The Bam citadel directed by M. Zahedian, Bam, the eastern gate of Iran directed by H. Emami, Bam, sustainable heritage, ICHTO, Bam in the Silk Roads series by NHK. 


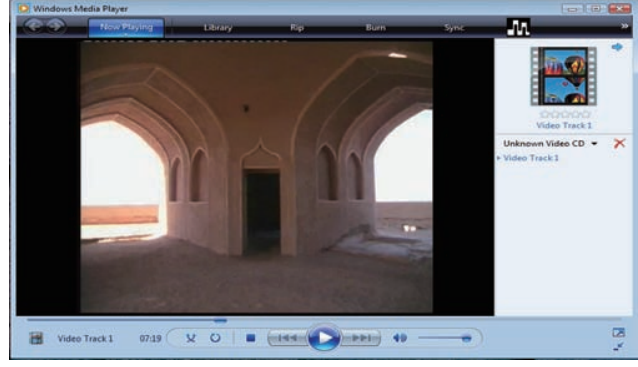

Fig. 13 Snapshot of the movie (credit by ICHTO) of interior of Four Seasons building.

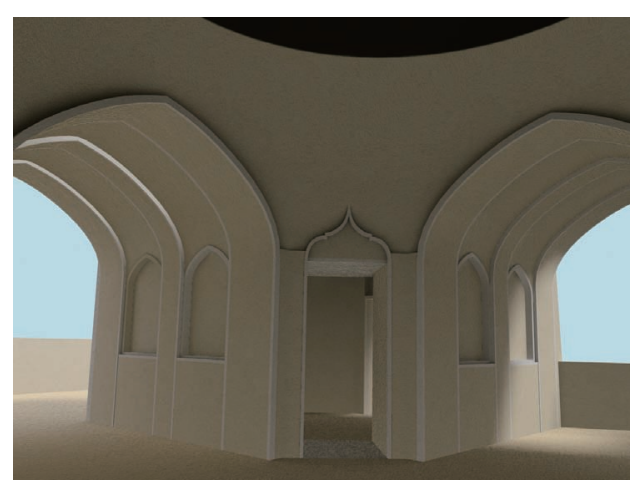

Fig. 14 3-D model of interior of Four Seasons building modeled from movie.

spaces for which no photos or maps were available (Fig. 13 and 14 shows images from a movie of the interior of the Four Seasons building and the 3-D model). Among the movie data was a movie of NHK's Silk Road series made in 1981 showing helicopter aerial shots. This was an especially valuable reference for modeling the upper part of the citadel.

Texts were used for disambiguating the changes in shapes during the restoration periods, discovering the history of the citadel and the buildings inside it, and describing the spaces. The textual references included annual reports on the restorations, unpublished papers about history and architecture, papers submitted to the first and second congress of history of Iran and Citadel of Bam (1374-78), and the Bam region report [1]-[3].

Oral survey of explanation of experts who worked at the citadel before the earthquake was done when no other information could be found. The sketches based on these explanations were drawn. Sometimes these sketches were made by comparing the target space with a similar style of architecture or construction.

\subsection{Data categorization, semantic annotation and pro- vision for 3-D modeling}

Most of the data listed above didn't have categorization or metadata. We made categorized them according to data type (maps, photos, etc.) and data location (names of buildings such as gate, and bazaar). Later, a reference guide map for the photos was drawn $u^{27)}$. For each building, the target image from aerial photos was extracted from among more than 40 important monuments within the $200000 \mathrm{~m}^{2}$ of the site. Furthermore, the movies were reviewed and the snapshots related to target buildings for 3-D modeling were annotated and specified. A metadata list of architectural maps was created and locations lacking facades and other details were specified on a guide map. Moreover, a 3-D cartography map of each building was extracted and saved in a separate DWG file.

Each team of 3-D developers were provided with a classified database of heterogeneous information related to the target building and their annotations (Fig. 15).

\section{Systematic and semantic 3-D model- ing}

For modeling selected cases of the main two axes of the site, despite having state-of-the-art 3-D modeling tools, we had to choose the most suitable techniques for the shapes of mud brick buildings from among a vast number of options and functions. The modeling was done with the $3 \mathrm{ds}$ MAX $^{\circledR}$ tool. Although this tool is good for modeling animations and games ${ }^{28)}$, it posed complexity for modeling components with curved shapes and vaults. The key approach was to select the most suitable function among the large options of the tool.

Because comprehensive software for modeling architectural buildings could not be found, different tools were used together to overcome the shortcomings of each one. Modeling buildings is better done by drawing precise lines. Auto $\mathrm{CAD}^{\circledR}$ tool provides better functions for drawing lines than MAX $^{\circledR}$. Therefore, in some cases, the basic lines of walls and arches were drawn as DWG files and then imported to MAX $^{\circledR}$ to complete the model.

The 3-D model of the Citadel of Bam has extremely complicated semantic information for each of its elements. First there are building types; then data re-

\footnotetext{
27) The map was provided by Ms. Maryam Nezari, formerly of the Bam recovery project, and Ms. Mahshid Jafarizadeh of the Bam recovery project.

28) Autodesk $3 \mathrm{ds}$ Max ${ }^{\circledR} 3 \mathrm{D}$ modeling, animation, and rendering software helps design visualization professionals, game developers, and visual effects artists maximize their productivity by streamlining the process of working with complex scenes. http://usa.autodesk.com/adsk/servlet/ index?id=5659302\&siteID=123112 [7 Jan, 2008].
} 


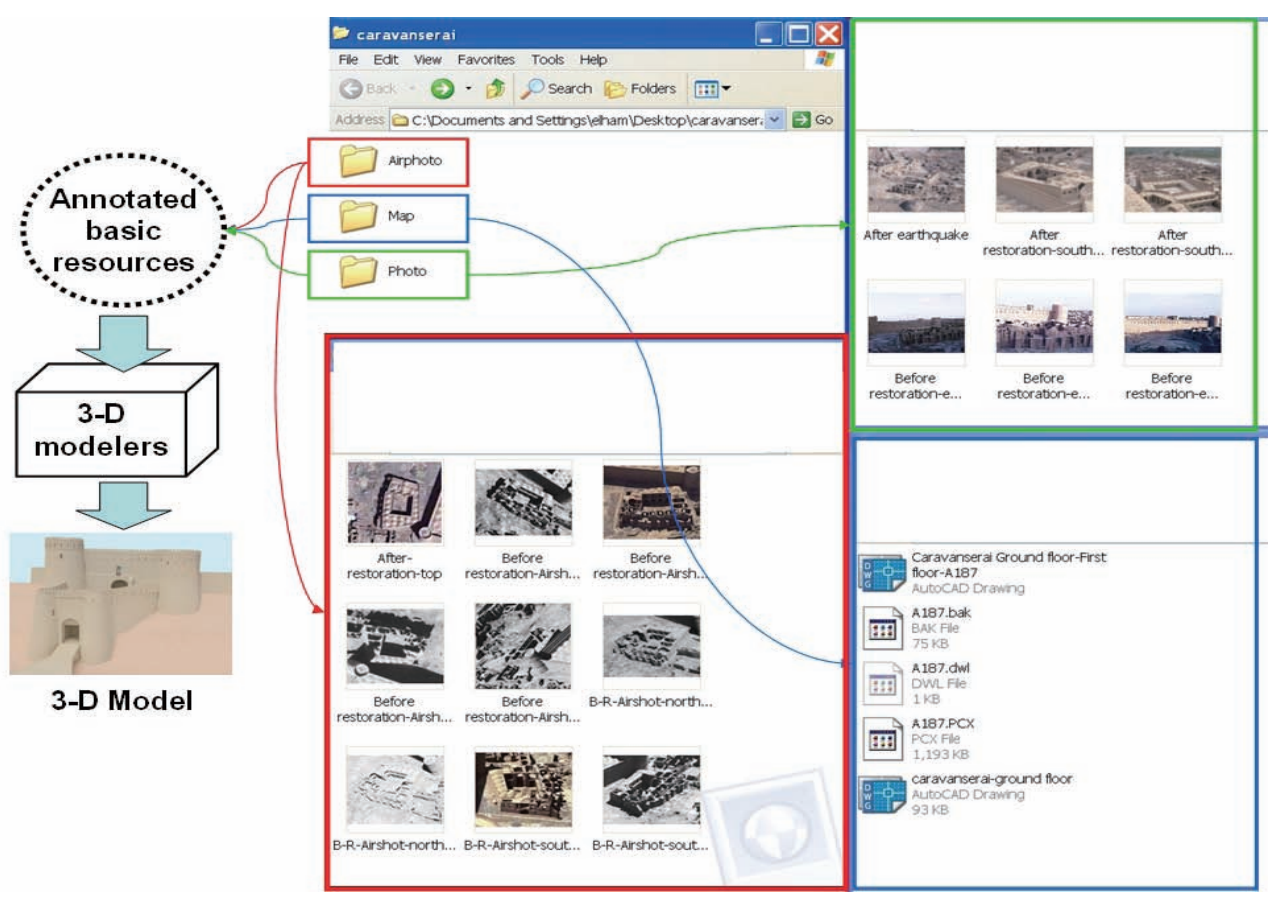

Fig. 15 Annotated primary data using different resources for 3-D modelers.

sources with different levels of accuracy and quality. Different groups were involved in developing the 3$\mathrm{D}$ models of the different buildings. All these factors made the systematic and semantic modeling essential.

\subsection{Layer management of the 3-D models}

To create semantic annotations of components, to coordinate and manage the process of drawing 3-D models between various teams, to avoid errors when merging the different models into a unified one and to control the correctness and quality of the modeling of different groups, the research team defined a systematic layer naming for the components of the 3-D model and created technical drawing guidelines for the 3-D model developers.

Layer management is the process of naming and making different categories of layers for the 3-D models according to their characteristics in the target building. The name of a layer corresponds to the semantic categories of the 3-D model. The layer names were kept short and written in such a way that different developers could easily recognize, define, and modify them; therefore instead of a word, a single letter indicated the specific subject in the layer. In some cases, these letters were different from international standard abbreviations. The reason was to make the names and usage shorter and more practical. ${ }^{29)}$

\subsection{Layer naming and related semantics}

The chosen 3-D modeling tool does not support the design of an advanced schema with a hierarchy of classes, attributes of classes, and instances (like ontology schemas). Hence, we devised a simple methodology similar to linguistic morphology ${ }^{30}$ ) by defining affixes to name different layers as a single string.

\section{Prefix}

Prefix indicates the most general information about a layer. In our case study, the prefix refers to the type of building (Table 2).

\section{Infix}

Infix specifies the data type. The 3-D model is based on the basic data resources such as architectural maps (plan, façade, sections). 3-D laser scans, 3-D carto-

\footnotetext{
${ }^{29)}$ For more specific information please refer to these references: Architectura Graphic Standards, 1912, 1951, and 1956; Time Saver Standards, 1966; Skidmore, Owings and Merrill Drafting Standards, 1986; Holabird \& Root Drafting Standards, 1987; Nagle Hartray \& Associates Standards, 1989; Murphy/Jahn Office Reference Manual, 1973; Braun/Skiba Standards Manual, 1990; Recommended Standards on Production Procedures (the so-called "POP Manual"), Northern California Chapter AIA, 1980; Graphic Communication in Architecture, William J. O'Connell, 1972; Interior Graphic and Design Standards, S.C. Reznikoff, 1986.

${ }^{30)} \mathrm{http} / / /$ en.wikipedia.org/wiki/Morphology_(linguistics) [7 Jan, 2008]
} 
Table 2 Layer management abbreviations for development of 3-D models.

\begin{tabular}{|c|c|c|c|}
\hline $\begin{array}{l}\text { Type of } \\
\text { Layer } \\
\text { Name }\end{array}$ & Abbreviation & Full Name & Description \\
\hline \multirow{6}{*}{\multicolumn{2}{|c|}{ Prefix }} & name & name of building identifying its function \\
\hline & & "Vague" & $\begin{array}{l}\text { The building doesn't have a name, there is a lack of data on the building, } \\
\text { or the building is small or less important (the 3-D model is conceptual). }\end{array}$ \\
\hline & & circulation & The component is part of a circulation element like a street. \\
\hline & & topography & topography of ground \\
\hline & & landscape & green spaces and natural scenery \\
\hline & & wall & city or defensive walls \\
\hline \multirow{7}{*}{\multicolumn{2}{|c|}{ Infix }} & 1 & imprecise maps (mostly surveyed before quake) \\
\hline & & 2 & precise maps (mostly surveyed before quake and corrected after) \\
\hline & & 3 & photos \\
\hline & & 4 & sketches by skilled experts \\
\hline & & 5 & maps of similar style of construction or shape \\
\hline & & 6 & laser scan \\
\hline & & 7 & 3-D cartography maps \\
\hline \multirow{10}{*}{ Suffix } & $\mathrm{r}$ & roof & \\
\hline & 1 & wall & \\
\hline & $\mathrm{f}$ & floor & \\
\hline & $\mathrm{w}$ & window & \\
\hline & $\mathrm{d}$ & door & \\
\hline & $\mathrm{t}$ & topography & topography inside the area of the building \\
\hline & o & ornament, decoration & \\
\hline & $\mathrm{g}$ & green space & little gardens in the interior spaces of houses \\
\hline & Suffix $+\mathrm{i}$ & interior component & component below the ceiling of a closed space \\
\hline & Suffix+e & exterior component & \\
\hline
\end{tabular}

graphic maps, and similar data are also basic resources. Photos, movies, and sketches are complementary resources. In some cases in which the building was destroyed, the sketches created by experts who remember its spaces are also used as reference maps.

The infix specifies the accuracy of the corresponding part of the 3-D model according to the basic maps. If the reference maps are inaccurate and the modeling is done based on the photos, then the 3-D model is not a 1 to 1 precise map. The list of infixes is given in Table 2 .

\section{Suffix}

The suffix specifies a building component or architectural element. Moreover, it specifies the location of the component in the building as an interior or exterior part. The suffixes mentioned here are simply defined as a single alphabet abbreviation of the component name (Table 2).

\subsection{Application and constraints}

The layer manager in MAX $^{\circledR}$ is a powerful tool for organizing and managing objects in complex scenes. It can be accessed by the function 'layer' from the main toolbar. Each layer has some attributes such as colour. The models were developed in the first phase of research by using the layer management method. It provides the modelers and users with the following opportunities:

- The quality control team can turn the layers off or on and analyse the components of the 3-D model without having to deal with complicated technical modeling details.

- It is possible to make one or more layers transparent (by changing the 'opacity' of the component in the 'material editor' function of $\mathrm{MAX}^{\circledR}$ ) and see the rears of the target component, and thereby to check the correctness of the drawing.

- It shows how the metadata corresponds to each component (type of building, type of data, type of architectural element, etc.)

- Each layer can have a different colour; it is easy to 
recognize when the components of the 3-D model interfere with each other.

- The user can search inside the 3-D models to retrieve specific components according to the layer management metadata.

- All the models are merged into a basic 3-D model without errors that can arise from files with similar names.

Fig. 16-21 show how this layer management is used to structure the model of the "Four Seasons" building.

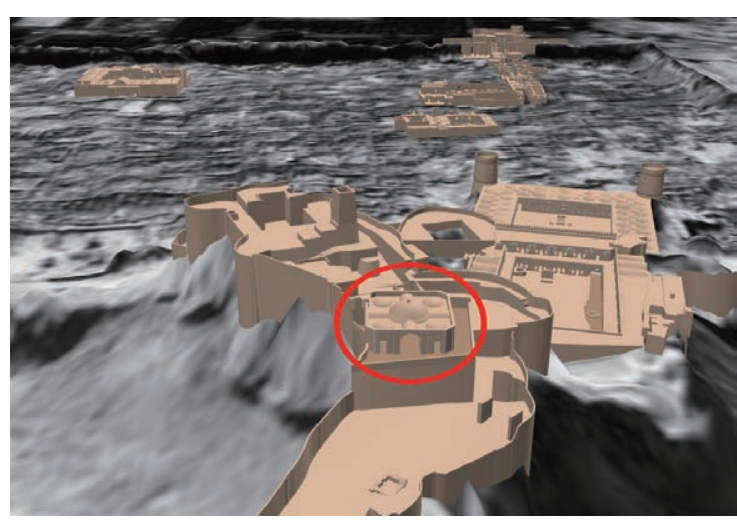

Fig. 16 View from the Four Seasons building of the other 3-D models of the Citadel of Bam developed in the first phase of research.

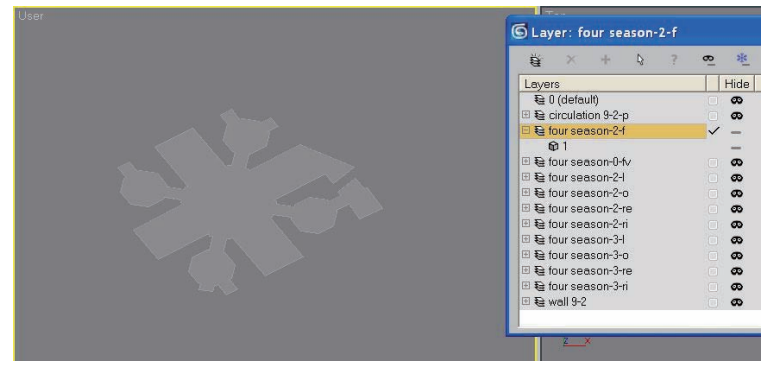

Fig. 17 Floor component and layer name "four season-2-f".

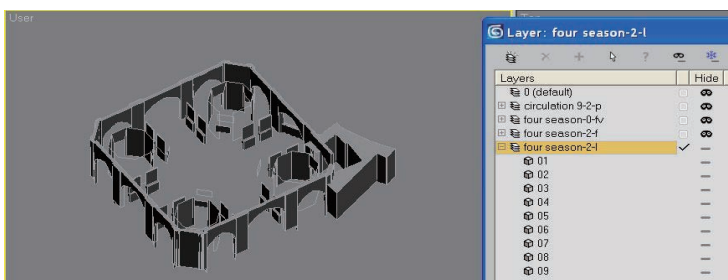

Fig. 18 Wall component and layer name "four season-2-l".
The space was once used as a reception room for distinguished guests and was located at the highest point of the citadel.

One constraint of using the layer-based 3-D model arises from the minds of the modelers. Normally in MAX ${ }^{\circledR}$ modelers build models with objects and group of objects. Layer management and layer-based 3-D modeling are originally based on AutoCAD ${ }^{\circledR}$, another product of AutoDesk ${ }^{\circledR}$. Although the modelers had difficulty in shifting from object-based to layer-based modeling, layer-based modeling provided a more systematic 3-D model and an opportunity to give semantic information to each component. Over the course of time, the modelers were able to adapt themselves and their results to the layer management techniques dis-

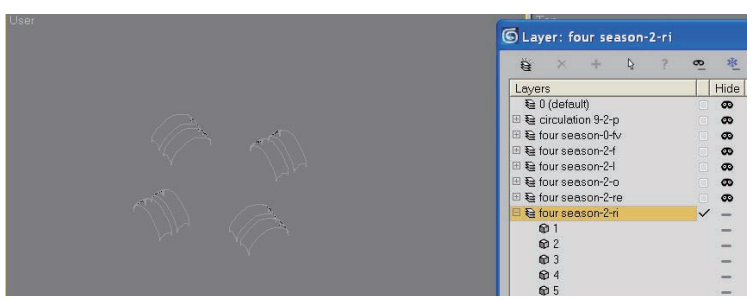

Fig. 19 Interior roof component and layer name "four season-2-ri”.

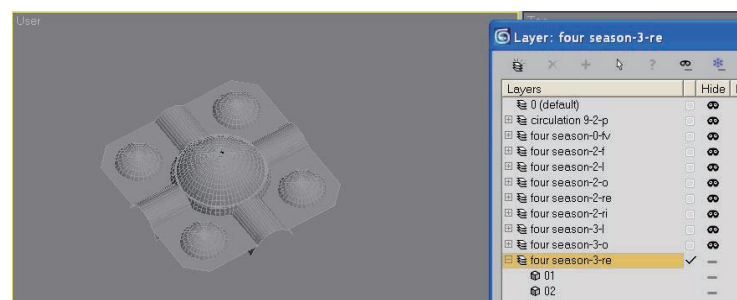

Fig. 20 Exterior roof component and layer name "four season-3-re".

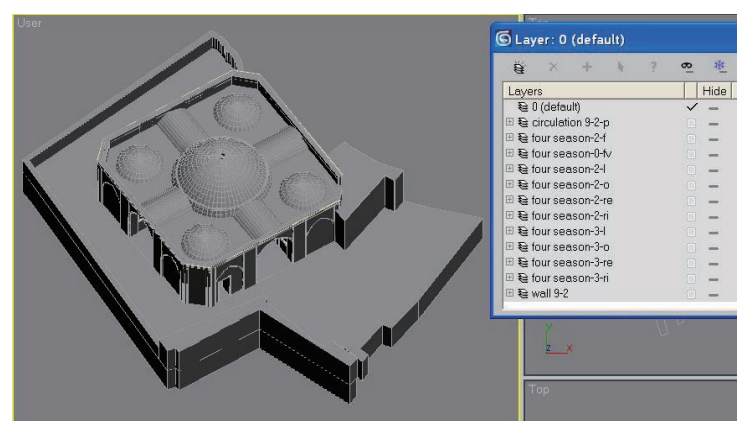

Fig. 21 Complete 3-D model of Four Seasons building and associated attributes. 
cussed above.

\section{$63-D$ modeling of entrance (main gate), bazaar, and Four Seasons building}

The modeling of entrance (main gate), bazaar and Four Season building was done by the University of Waseda team ${ }^{31}$. The entrance (main gate) of the citadel was the first case selected for modeling. Here, we give a sequential description of the modeling tasks. Note that the reference of the 3-D reconstitution is the shape of the entrance just before the quake. This is different from the original shape before the restoration process.

\subsection{Process of modeling}

The entrance was modeled with a specific method as it was connected to the rampart in an irregular architectural shape. Here, we explain the modeling process and the functions of MAX ${ }^{\circledR}$ that we used for this pur$\operatorname{pose}^{32)}$.

To make the walls, we traced the lusterware image in the plan with Adobe Illustrator ${ }^{\circledR}$, then imported the lines and Bezier curves to MAX $^{\circledR}$ to convert each into a spline object. After the conversion, we applied the 'Loft Modifier' together with the height extracted from the elevation data to make the wall. Modeling the entrance itself required us to reproduce the curved shape on three axes. For this, we traced three plans at different heights, imported them, converted them into spline objects, and arranged these objects according to the converted plan of the heights extracted from the elevation data. In addition, the top of each object was related by a 'Crossing Session Modifier' to make wire fame, and a surface was made for the wire frame. We transformed the wire frame by using free form deformation (FFD) while referring to the original photograph to complete the curved wall. For the battlement of the entrance wall, we traced the elevation to get the spline shapes and pushed it out to make the bare-bones model; finally we transformed the bare-bones model by using FFD along the wall (Fig. 22 and 23).

For architectural elements like doors and windows, we made the entrance part with a door-object making tool. During the modeling, we referred to the photographs to decide the number of glass windows, the width, etc., of the window frame. We referred to the latest photos of the entrance taken just before the earthquake.

Modeling the Four Seasons building involved mak-

\footnotetext{
31) This part introduces the models which are developed under supervision of Associate Prof. Dr. Takashi Kawai., Mr. Nobuaki Abe (for the main gate (entrance) and Four Seasons building and Ms. Asaka Ito and Mr. Ha Young Yoon (master's degree student of Waseda University) for the bazaar.

${ }^{32)}$ The functions of MAX $^{\circledR}$ are cited inside quotation marks, e.g., 'Polygon Edit Modifier'.
}

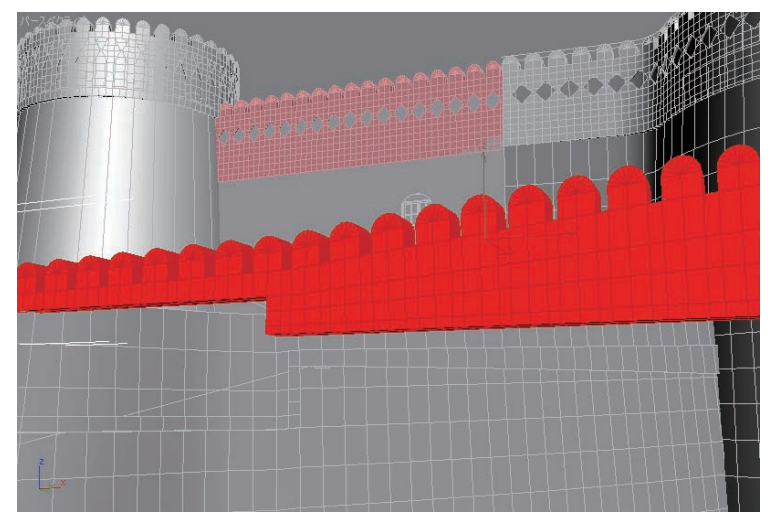

Fig. 22 Modeling of battlement before transformation using FFD.

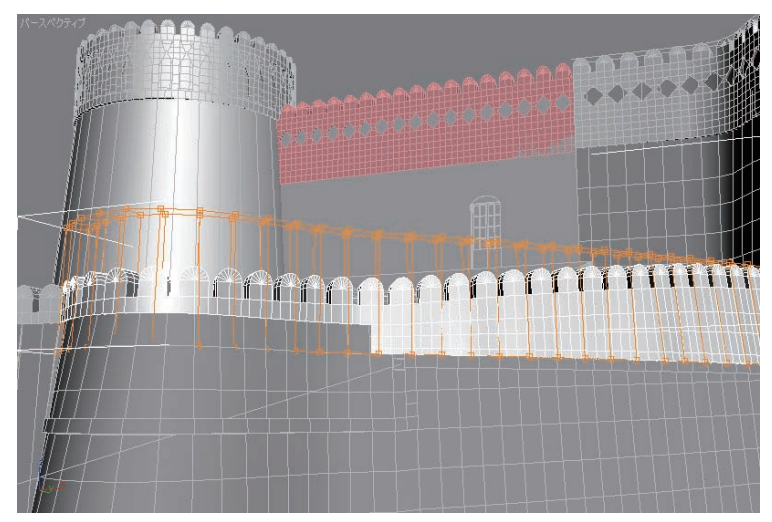

Fig. 23 Modeling of battlement after transformation using FFD.

ing less complex shapes but more decorations. We started making the roof of the dome by referring to its shape in section or elevation. First, we displayed the lusterware section image of the elevation with Adobe Illustrator ${ }^{\circledR}$, and traced it with Bezier curves. The curves were imported to $\mathrm{MAX}^{\circledR}$, and after rotation around a central axis were converted into the face of the dome by using 'Lathe Modifier'. In the final step, we performed transformations by comparing the model with the original photograph (Fig. 24).

To make the chalk-band decoration (ornament), we used an edge made by using Boolean or Shape Merge. First, we selected the edge with the chalk band, and then cloned the spline to be extruded after applying the 'Extrude Modifier' to get the depth; we applied it with necessary thickness by using the 'Shell Modifier' to complete the model. 


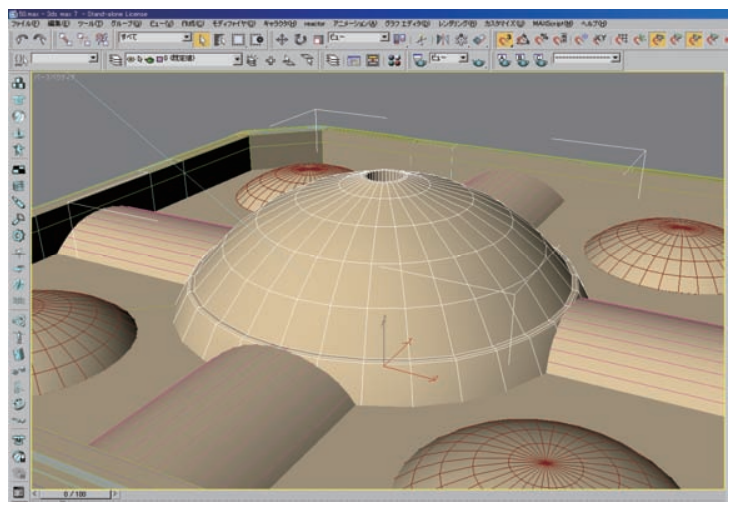

Fig. 24 Roof surface of the dome of the Four Seasons building.
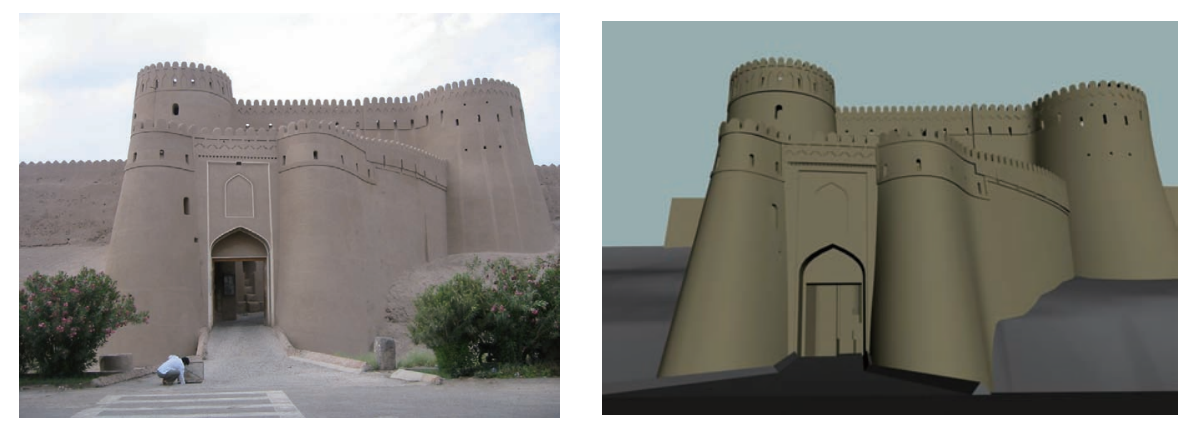

Figs. 25 and 26 Reference photograph used for camera matching (left, photo credit: ICHTO), and image rendered from the same aspect as the reference photograph (right).

\section{Camera matching technique}

The use of photographs taken before the earthquake has played an important role in this project. In particular, rendering of the CG model from the same aspect as these photograph materials has made it much easier to make comparative study of the CG model and the photograph material (e.g., compare Figs. 25 and 26). To do so, we used the 'Camera Match' utility. To find the common characteristics of the photos and model, the camera setting was calculated for when the specific photograph was taken. After that, we reproduced the same camera setting in a specific scene of the CG model. This enabled us to render from the same aspect as the original photograph (Fig. 27).

\subsection{Process of adjustment}

The camera match technique has a number of difficulties; its accuracy is especially a problem. However, comparing the ruins before the earthquake with CG restoration model at the same angle was an effective way of modeling and correcting decorative parts like small holes in walls and the precise shapes of arches.

The shapes of model elements such as arches were corrected after receiving the expert evaluation (section 8) (Figs. 28-30). As can be seen in the figures shape of the arch was modified according the photo and the guidelines provided by the evaluators so that it properly replicated the original one.

Since the CG model was based on an unreliable plan, we collated it with cartography data and corrected it when necessary. After allocating 'Polygon Edit Modifier', we stretched and corrected the model by using 'soft selection'. Before making the corrections, we compared the 3-D cartography data with aerial shots taken from the building in a movie that was made before the earthquake (Figs. 31 and 32).

\section{3-D modeling of mosque, Sistani house, Tekkiyeh, barracks, and sta- ble}

The University of Tehran team developed detailed 3 D model of five cases among the important buildings ${ }^{33)}$.

33) This part introduced the 3-D models developed under the supervision of Associate Professor Dr. Alireza Einifar and M. Arch. Mr. Said Einifar and the Raazahaang company's team of 3-D developers, Mr. Human Kian-Ersi, Mr. Pouya Khosro Jerdi, and Mr. Morteza Hengofti in modeling the tekkiyeh, Sis- 


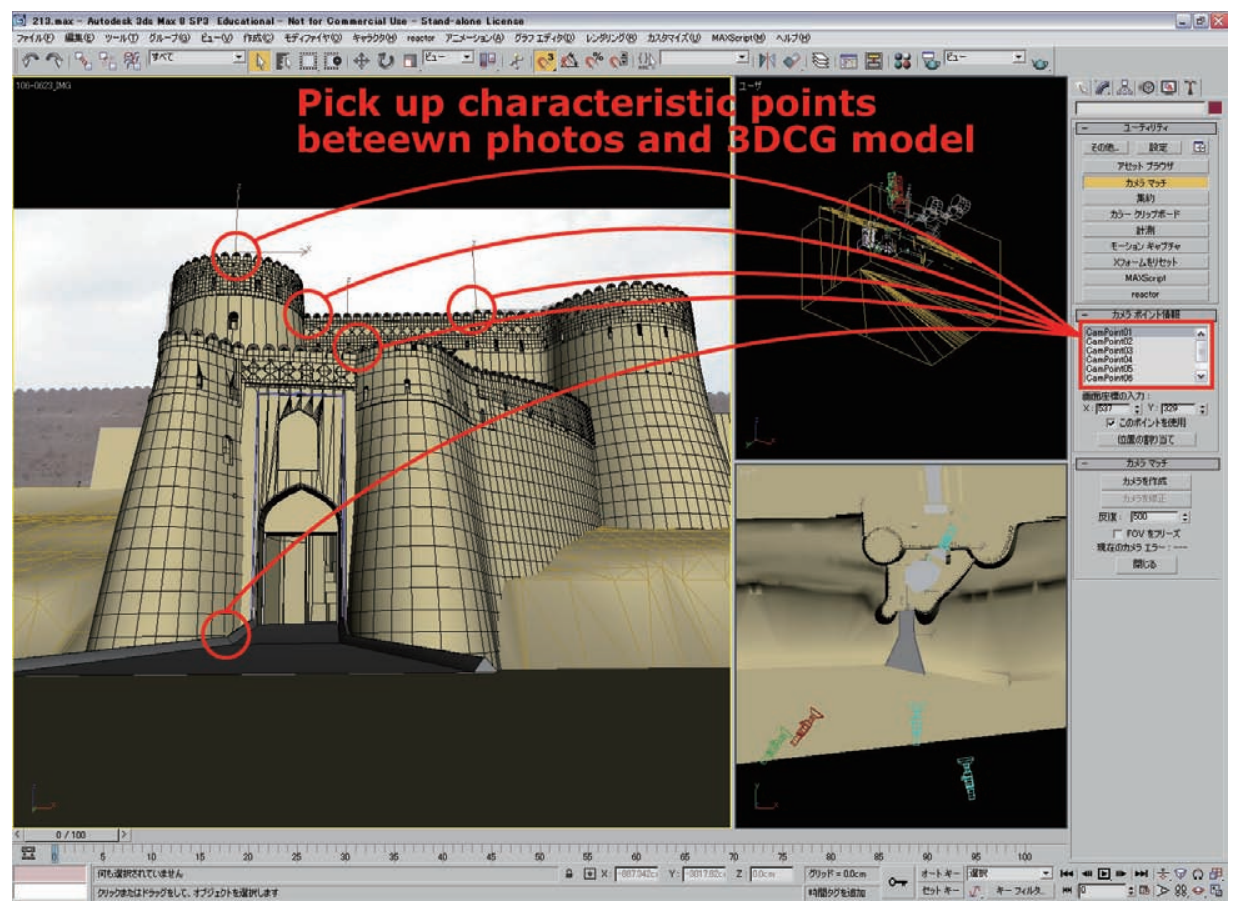

Fig. 27 Snapshot of "Camera Match" utility inside MAX ${ }^{\circledR}$.
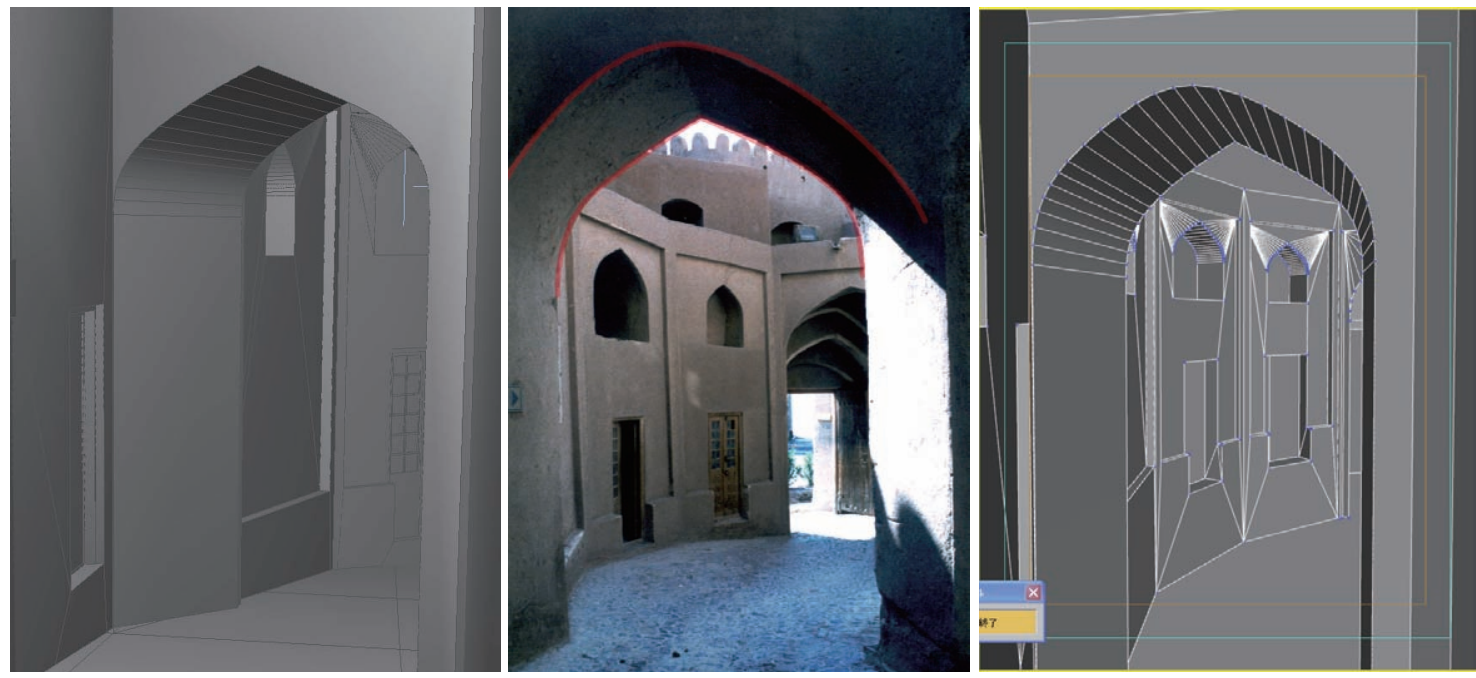

Figs. 28, 29 and 30 Example of arch shape modeled from elevation data (left), original photograph (middle, photo credit: ICHTO), and transformed arch shape based on the photograph (right).

The Mosque was the main prayer place in the citadel and one of its most ancient buildings. Sistani house was a precious house of a noble inhabitant and had been the main office of ICHTO in Bam before the earthquake. The Tekkiyeh was a religious and ceremonial place for

tani house, mosque, barracks, and stable. mourning, the performance of rituals, and the holding of historical-religious events. The barracks housed the army and governor's soldiers; the stable kept army and government horses. All these places were of architectural excellence and key places in the citadel. 

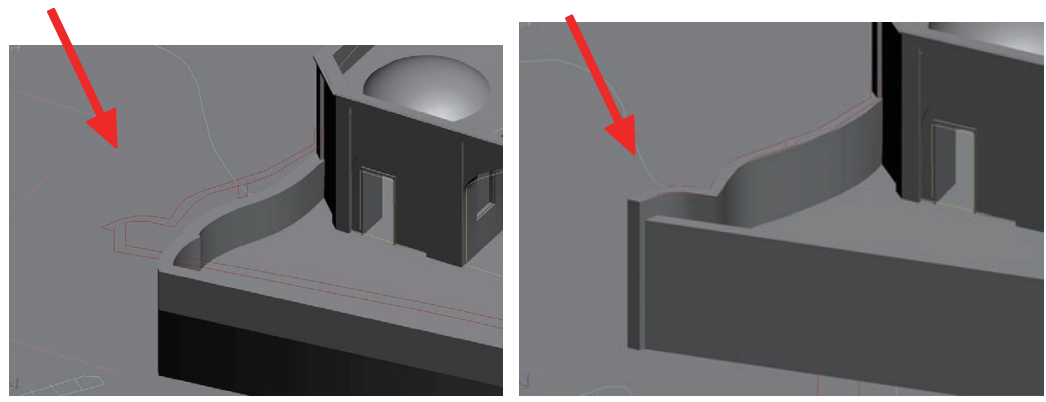

Figs. 31 and 32 Modification of the 3-D model of Four Seasons building (in grey) by referring to 3-D cartography map (red lines). Before adjustment (left) and after adjustment (right).

\subsection{Process of modeling}

To draw the 3-D model of the five case studies, the first step was to modify the basic maps in the AutoCAD ${ }^{\circledR}$ software. The modified maps were imported from DWG or $\mathrm{DXF}^{34)}$ to MAX, and the geometry, layers and spline rendering parameters of the imported file were then adjusted. In the primary models, the data were used to draw the solid volumes of external spaces.

The next step involved drawing the internal and external spaces by referring to the technical drawings and layer management guidelines (see section 4). In this step, the 3-D cartography map (see section 3) was used to draw the external roof layer ${ }^{35)}$.

Buildings were primarily modeled without ornaments. Each building component like a floor, roof, wall, etc., was similarly modeled in 3-D, in separate layers and with specific borders. This was a difficult task as the software did not provide good options to define precise borders of architectural elements. We tried to reduce the intersection of volumes and make the border of each element explicit.

Each floor was drawn in a separate layer as an independent volume. Walls and pillars were excluded from these surfaces. Based on technical guidelines, elements such as stairs which arose from the floor were considered to be part of the floor layer. Ceilings and roofs were defined as internal and external roofs, respectively. They were drawn as separate surfaces in different layers. 'Mesh' was adapted for drawing ceiling surfaces with regular shapes. Some irregular roof surfaces were created by 'poly modeling'.

The modeling of the ceilings was a challenge because of the serious lack of 2-D maps. The models were

${ }^{34)}$ Drawing Interchange Format, or Drawing Exchange Format of AutoCAD ${ }^{\circledR}$ files.

35) The roof of the tekkiyeh was an exception. The reason was lack of in formation on the cartography map. In this case, aerial photos taken after the restoration process were used.

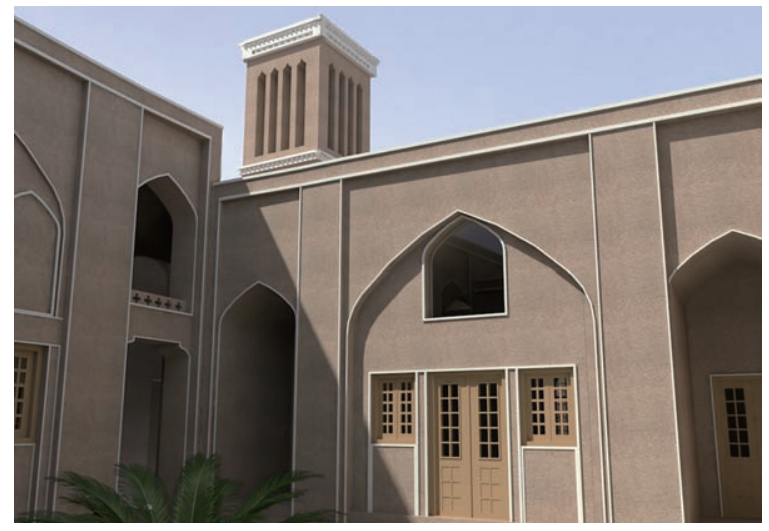

Fig. 33 3-D model snapshot of Sistani house, from the main yard toward the wind catcher tower after rendering.

based on pre-earthquake sections, very limited numbers of photos, and a technical analysis of the construction methods. Sometimes, the arched shape of the ceiling was reflected in the facades and could be modeled from them. In most cases, the structure of the vault and ceiling influenced the 3-D cartography map of the roof. Therefore, the ceiling was controlled by the roof surface that was modeled according to the 3-D cartography map. One problem was the incompatibility of the internal and external surfaces of the roof in some places that were drawn using two different sources. The 3-D cartography map was used as the reference for modifications to minimize the errors in the thickness between roofs and ceilings (Fig. 35).

Modeling the facades was easier because we had access to better photos and maps. But in most cases, the arches were not correctly drawn in the 2-D maps. Therefore, the geometrical methods for drawing different arches provided by the team of evaluators of NII were important guides for modeling facades. Snapshots taken from the model of Sistani house and model of the 


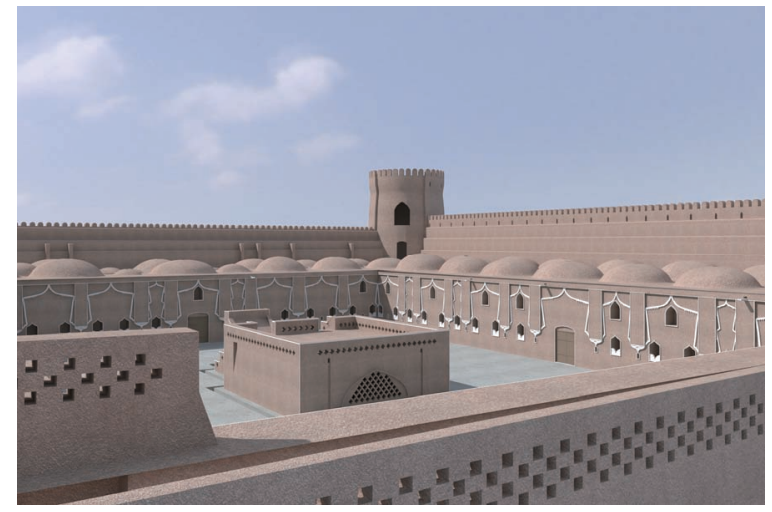

Fig. 34 3-D model view of the stable after trial rendering and texture mapping.

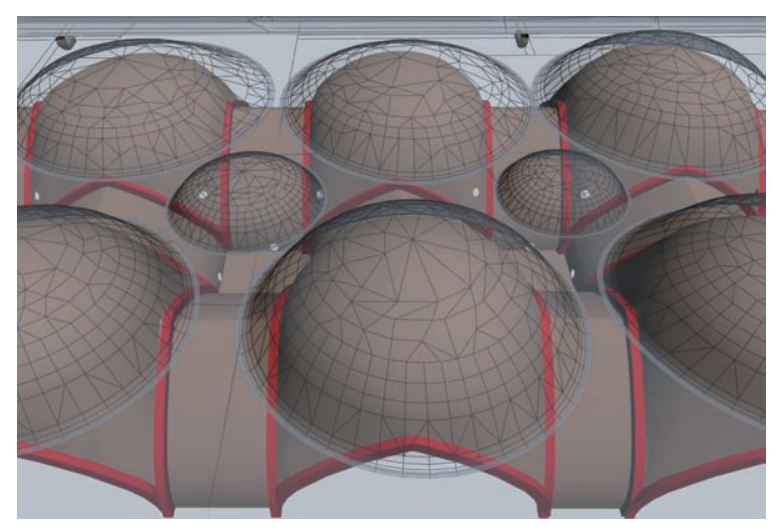

Fig. 35 Inner and outer arches and vaults of roof of the stable model. stable are shown in Fig. 33 and 34.

The 3-D cartography map was used to smooth the appearance of the external roof surfaces. The mesh of the external surfaces of the roof had to be reduced for the files of the 3-D model to be able to be imported to the VR environments without error. In this case, the 'optimize' function was used to reduce the number of meshes and polygons.

\subsection{Process of modification}

The 3-D modeling of mud brick buildings with traditional arches, vaults, and details was a new experience for the team. Each 3-D model was corrected (and in some cases remodelled) in three major stages according to the evaluation report of errors provided by the team of supervisors (see section 9). For example, Fig. 36, 37, and 38 present these three stages for the model of the main iwan of the mosque. The details and shapes were enhanced in the photos. The modelers gained valuable lessons for modeling similar buildings.

\section{Drawing of ornamentations}

Ornamentations were categorized into four types. The most common ornamentations were chalk bands. These were in fact an aspect of a construction technique for controlling the borders of geometrical volumes between chalk and mud-straw covering and were lead frames for constructing the arches. The chalk bands were added to the models as a general group of ornamentations. These ornamentations were drawn as separate volumes using the 'mesh modeling' function and were adjusted to the main volume of the building. These ornaments were fixed in the right place by using the 'locking' function. The general ornamentations also included ornaments on the external walls of the stable.

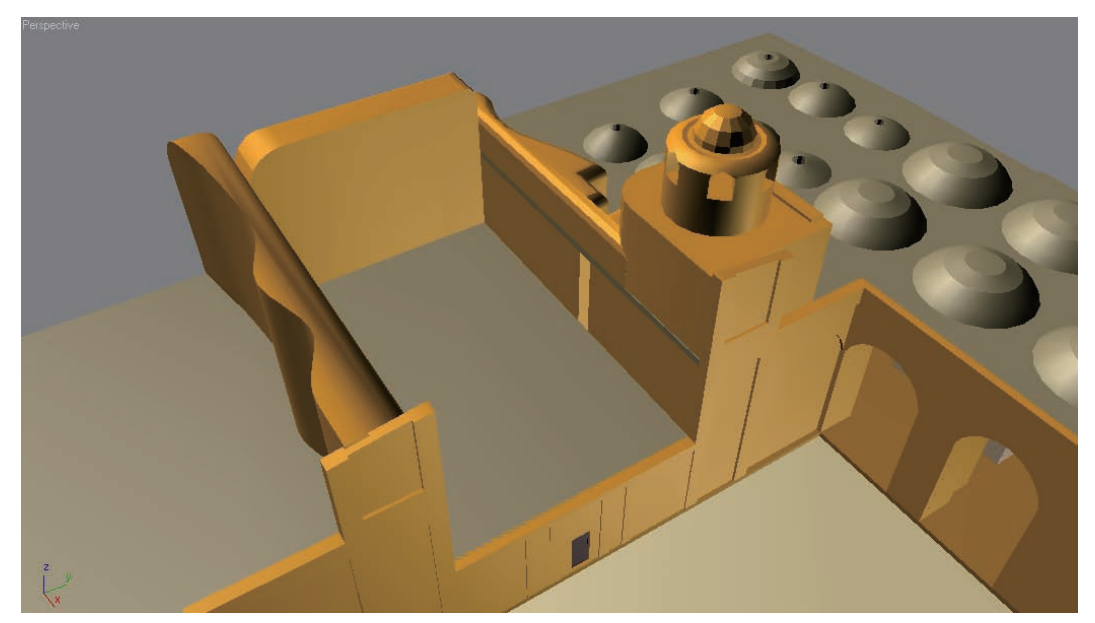

Fig. 36 Preliminary model of mosque, ancient iwan (Feb. 2006). 


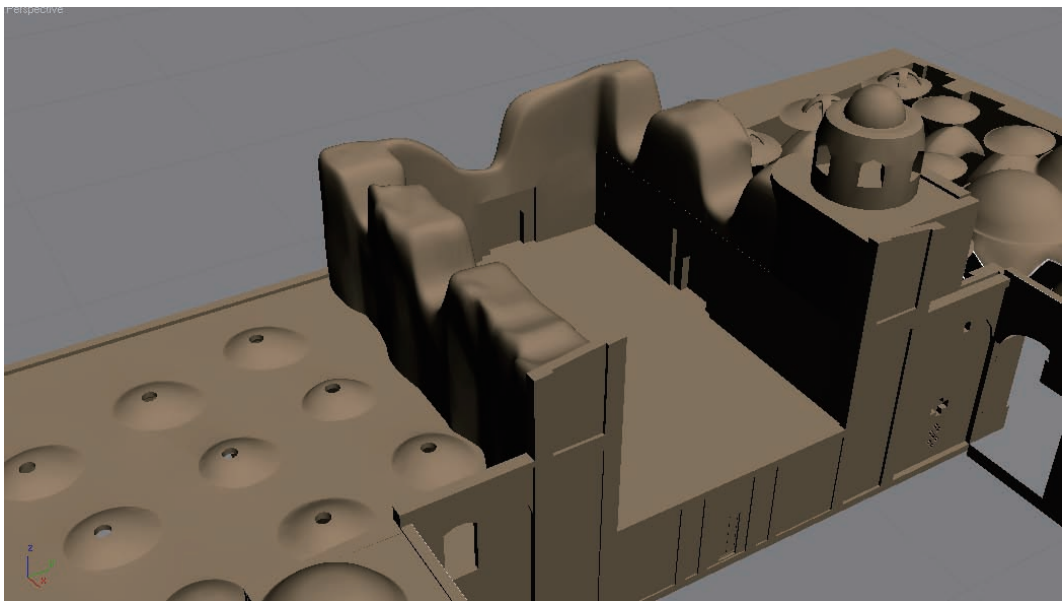

Fig. 37 Corrected model of mosque, ancient iwan after some modifications (Feb. 2007).

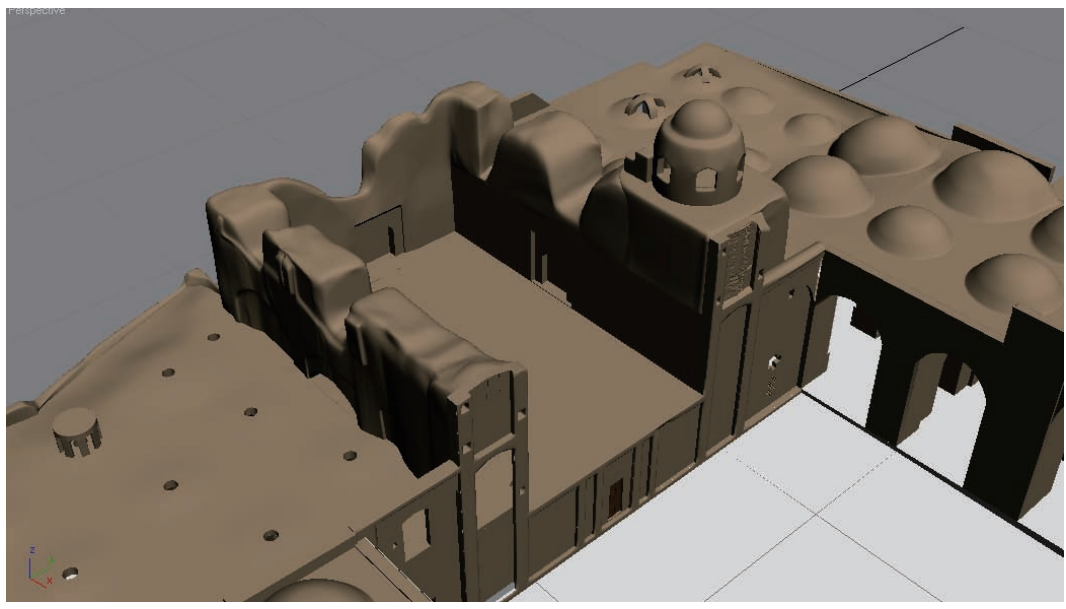

Fig. 38 Final model of mosque, ancient iwan after correction and modification (Oct. 2007).

They were drawn by 3-D modeling instead of mapping (Fig. 42).

In addition to these general ornamentations, there were three specific groups that needed combinations of different MAX functions to draw. These groups included the 'muqarnas'36) of one of the mosque's 'mehrabs' ${ }^{37)}$, mud brick details on the stable towers,

36) Use for the network of small, repeated cellular forms resembling bottomless niches and sometimes corbelled and structural, more often suspended and decorative, which form the undersurfaces of vaults and domes common in Islamic architecture. (from

http://www.getty.edu/research/conducting_research/vocabularies/aat/ [7 Jan, 2008].

37) Mehrab is an arch recess in a mosque indicating the direction of the Qebleh and where the 'Emam-e Jama'at' stands. Qebleh is direction toward which prayers are rendered and Emam-e Jama' at is a person who, in a congregational prayer, stands in front of the congregation and is followed by it in the ritual (Haji-Qassemi, 1998). and the chalk decorations and fire places of rooms on the first floor of the stable. Modeling of these ornamentations required various techniques, such as 3-D drawing of volumes and mapping of two-dimensional patterns.

\section{- Muqarnas}

There are muqarnas ornaments in the two 'mehrabs' of the mosque and in one of the fire places on the first floor of the stable. The largest and complicated one in terms of geometry was the main mehrab of the mosque. Muqarnas ornaments are complicated geometrical forms, and are defined as a 'type of roofing harmoniously combining concave elements of equal size' [13]. The rational way of modeling the muqarnas is to find and draw it from precise two-dimensional ge- 


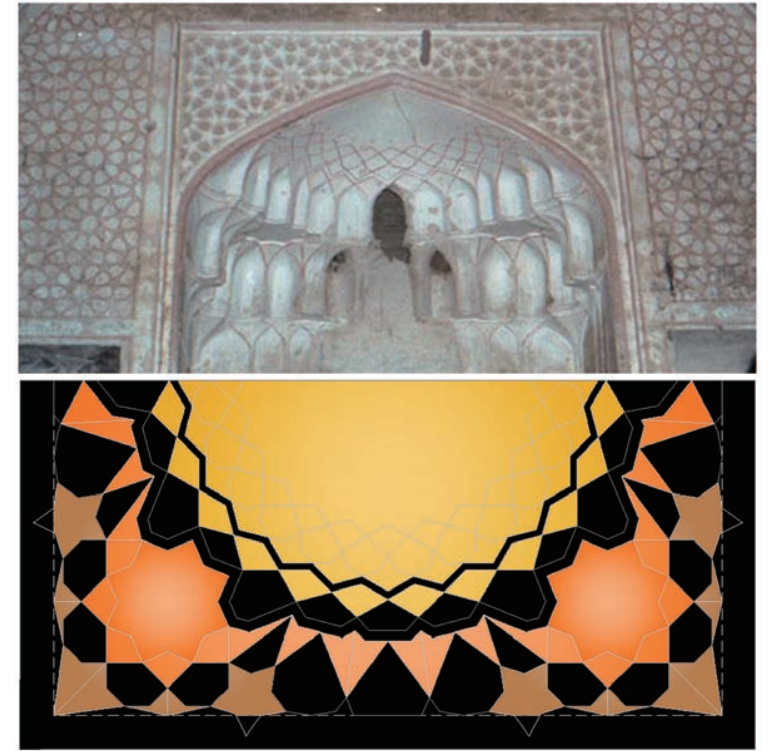

Figs. 39 and 40 Photo of muqarnas of the mosque and its geometry generated using AutoCAD ${ }^{\circledR}$ software.

ometrical plans and its elevation. The pictures of the muqarnas were thus analysed and compared with other sources on the geometry and categorization of muqarnas (for instance, Lorzadeh, cited in Raees-zadeh and Mofid [14]), and muqarnas maps of three levels were drawn (Figs. 39 and 40). The 3-D model was drawn by finding the heights of these detail from pre-earthquake photos. We used the 'NURBS ${ }^{38}$ ) modeling' function. One important point here is that there are differences between the pre-earthquake data and the drawn model. These differences arose from the restorations conducted in different times, which have caused errors in geometry. Further work would entail modification of the muqarnas volumes based on the pre-earthquake photos and its real appearance.

- Mud brick decorations of stable tower

The stable building had two towers in the south-west and south-east corners. Both towers had mud brick ornaments. These ornaments were restored with clay and straw covers. Before the earthquake, part of the mud brick ornaments of the south-east tower had been uncovered, whereas the ornaments of the south-west tower had been completely covered by mud and straw. Photos from before the earthquake were used as basic information for drawing the ornaments.

In addition to the ornamentations, there were holes in the walls of the towers that had to be represented in the

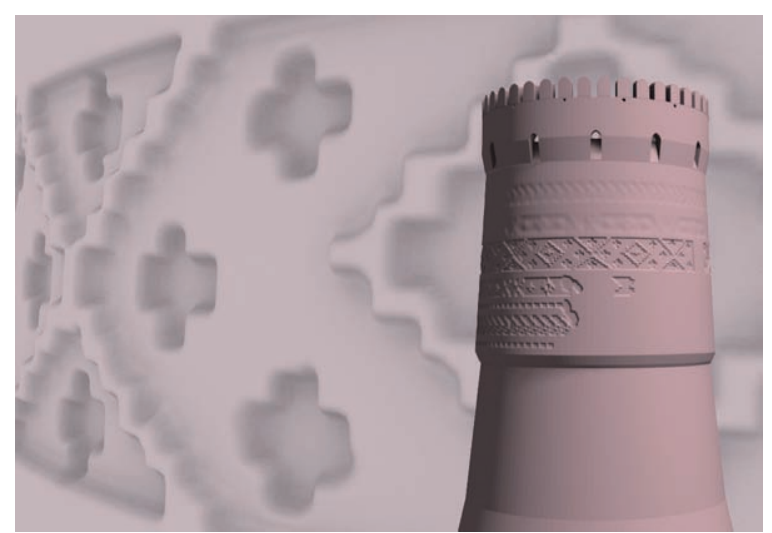

Fig. 41 3-D model of the mud brick work decorations of the tower of the stable.

models. The holes' two-dimensional pattern was drawn and edited in Adobe Illustrator ${ }^{\circledR}$, and then the pattern was matched with the surfaces of the towers. The third step used 'displacement' function of MAX to change the pattern into a 3-D model, and the model was edited by 'poly' modeling. The fourth step was to smooth the covered and uncovered ornamentations by using the 'subdivision surface' in the 'editable poly' function of MAX (Fig. 41). Although, this drawing provided a precise model of the towers, the file was quite large. The whole stable model would become very large if these files were added to it. The problem was thus how to reduce the number of meshes, while maintaining the model's quality.

- Chalk decorations of room on first floor of stable

The house of the 'Mir-Akhor' (the stable keeper) is located on the north-west side of the first floor. It contains three rooms, and each room has a decorated fireplace (Fig. 42). The main challenge for modeling this house was the need for a combination of 3-D modeling and mapping. The main volume of the fireplaces was made by 3D modeling. Two-dimensional patterns were drawn from photos by using Adobe Illustrator ${ }^{\circledR}$. These were mapped and adjusted to the 3-D model (Fig. 43). In addition, there were small muqarnas on the top of the fireplace in the middle room. The muqarnas drawings were based on information extracted from photos by using the camera matching technique (Fig. 44). The modeling team checked resulting models against the field survey data.

${ }^{38)}$ Non-Uniform Rational B-Spline. 


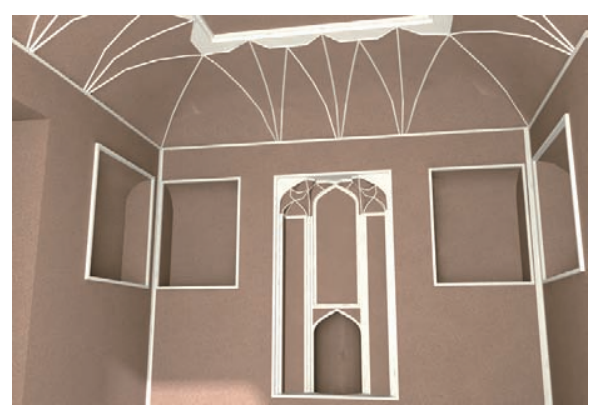

Fig. 42 3-D model of chalk-band decorations on first floor of the stable (after rendering).

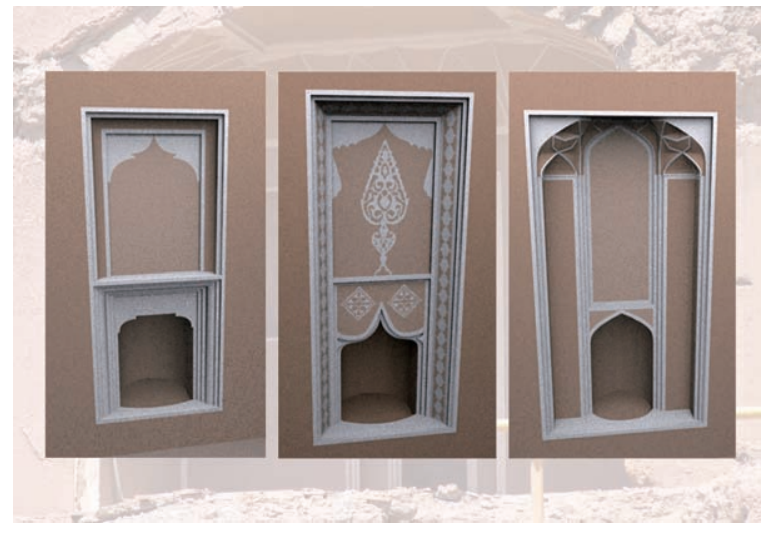

Fig. 43 3-D model of chalk-band decorations, different methods of mapping with photo (left, middle) and 3-D modeling (right).

\section{3-D modeling of caravanserai (small) and school (Mirzanaim)}

\subsection{Survey data}

3-D models of the school and caravanserai were made by the EVCAU team ${ }^{39)}$. The basic documents, including the maps and a few sections of bitmap type (scanned images), and documents from before the restoration process were incomplete. As the models must show the buildings after they had been restored, the lack of data was a serious problem.

A few low-resolution aerial photographs offered few details and were from three different periods: before restoration, after restoration, and after the earthquake. Unfortunately no photographs showing details of the interiors of these buildings were available. The 3-D cartography in DWG format showed the contour lines on

39) This part introduced the 3-D models which are developed under the supervision of Associate Professor Dr. Olivier Bouet and M. Arch. Frank Chopin headed by Mr. Andr Del and the EVCAU students for modeling small caravanserai and school of Mirza Naim by Ms. Vida Gholipour, Mr. Benoit Guillou, Ms. Sahar Ghaderi and Mr. Majid Bequali.

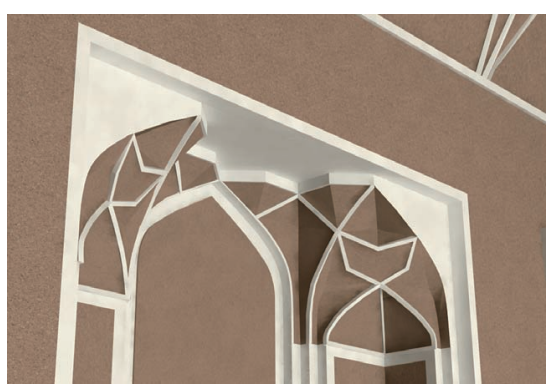

Fig. 44 3-D model of muqarnas with chalk-band decorations on the first floor of the stable.

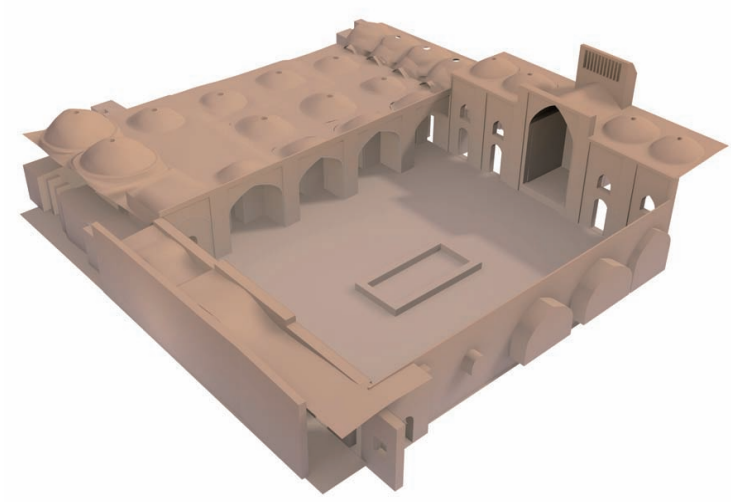

Fig. 45 Preliminary 3-D model of school of Mirza Naim.

the domed roofs of the buildings.

The imprecise documents were used in preliminary modeling that experimented with a variety of modeling methods (for instance, 'Patch modeling' or using 'space warps' for the roofs), as shown in Fig. 45 and 46 that would allow for future refinements. The preliminary models had to fit the 3-D cartography map as shown in Fig. 46. We explored various methods of modeling (Patch, use of the surface tools, NURBS, for editing curves and surfaces, spline extrusion, mesh, polygons, displacement mapping). However, because the basic data had such low precision and resolution, a new physical survey of the site had to be done to get enough data.

\section{Survey}

A survey of the citadel of Bam was conducted during a workshop in January 2007. This survey, which initially was intended as a guide to completing the modeling, motivated us to modify the content in a fundamental way. After the survey, we found the following shortcomings:

For the Mirza Naim school: 


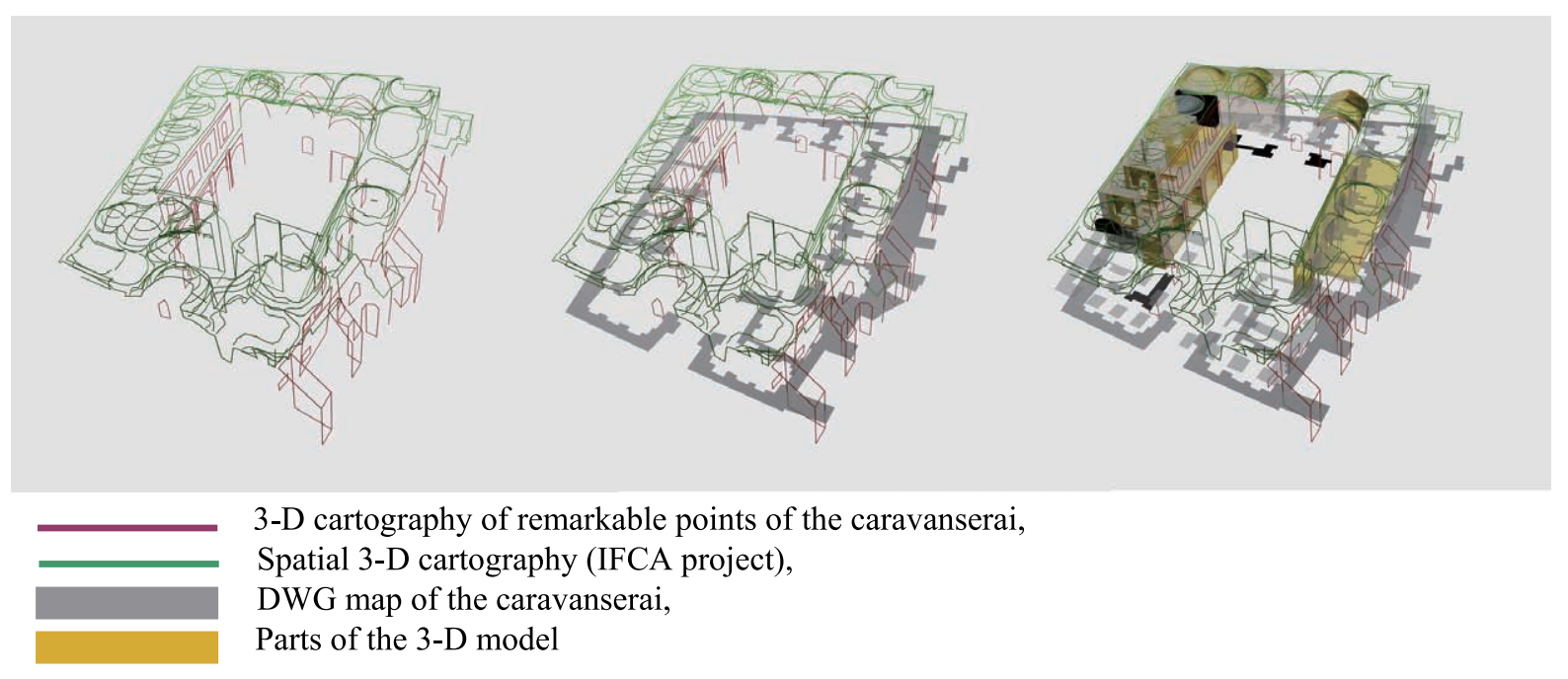

Fig. 46 First trial of comparative 3-D modeling of small caravanserai.

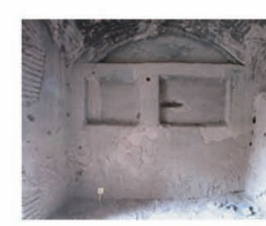

N

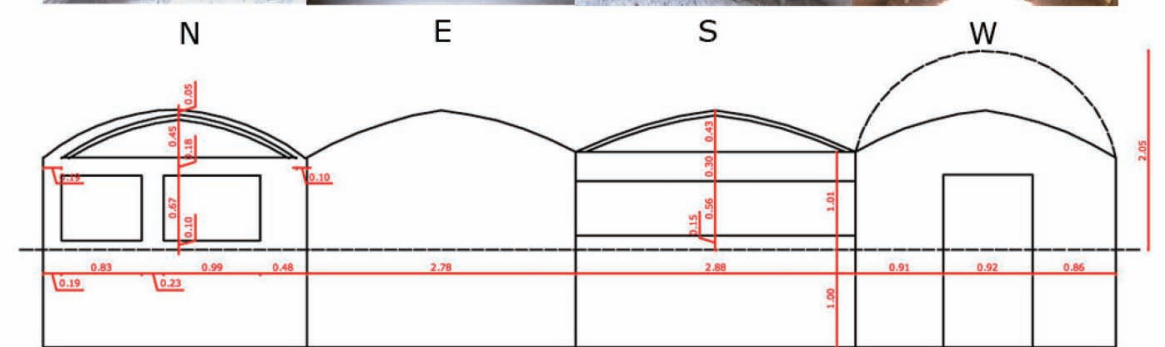

Small Cararavanserai Room 0_06 Photographs and inside elevations

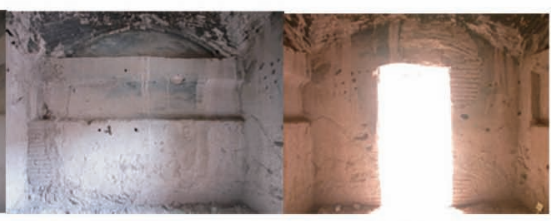

S

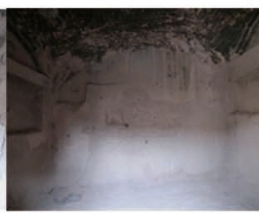

E ces in ground levels.

- Differences in ground levels.

- Differences between the original plans and the surveys.

- Few systematic and regular categorizations of niches and details. Each room had to be treated independently.

- Difficulty in distinguishing the borders of the building from nearby buildings (The school of Mirza Naim is surrounded by three adjacent houses).

- Missing parts for which the only available documents were sketches based on recollections of ex-
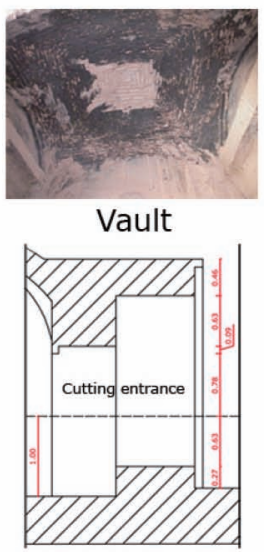
Photographs of every part of these buildings, their interiors and external frontages, and details were systematically collected and indexed in a database.

Sketches and surveys were added to the database. 3-D cartographic data were also collected with a 3D measuring system (Total Trimble Station 3600) as a complement to the 3-D cartography from the IFCA project. The measuring points were remarkable spots, and they were used as control elements of the model.

\section{Metadata management of surveyed information}

The whole data set became the subject of a systematic nomenclature; each room has a name, a level number (ground floor, first floor, etc.) and a number order beginning with the rooms facing north. Each part was described using photographs, sketches and computer drawings in DWG and DXF formats. The vaults were classified by their method of construction (barrel vault, cloister vault, etc.), and the niches were also classified. The various materials were also classified (Fig. 47).

This information was important for precisely generating data to reflect the changes in the geometry of the buildings that occurred over time and from deformations of the ground. They were not used as basic data, but as supplementary data for checking and modifying other recorded data as shown in Fig. 48.

\subsection{Process of 3-D modeling Approaches}

Different techniques can be applied to develop 3D model surfaces (Fig. 49), and the modeling teams took two approaches. The first was a mixed modeling that started on AutoCAD ${ }^{\circledR}$ and continued on MAX $^{\circledR}$; the other was done entirely with $\mathrm{MAX}^{\circledR}$. There are risks to modeling entirely in $\mathrm{MAX}^{\circledR}$. All the resources are used, but more particularly editing polygon and meshes.

\section{Two aspects and emerging them}

Here we introduce 2 aspects of modeling which can be emerged for the case of this research. The strategic aspect is the choice of the assembly of various building elements. It is important to determine the fragment that needs to be assembled given the constraints on the various objects which compose them, their partitions or their connections as referred to in the guidelines (see section 4).

The technical aspects of modeling (that requires knowledge to make rigorous and precise model) can be continued until the individual handling of a great number of vertexes.

With a view to future model development, the dependence techniques that can be used for relational modeling would seem judicious. However these techniques suppose to have complete knowledge of the compo-

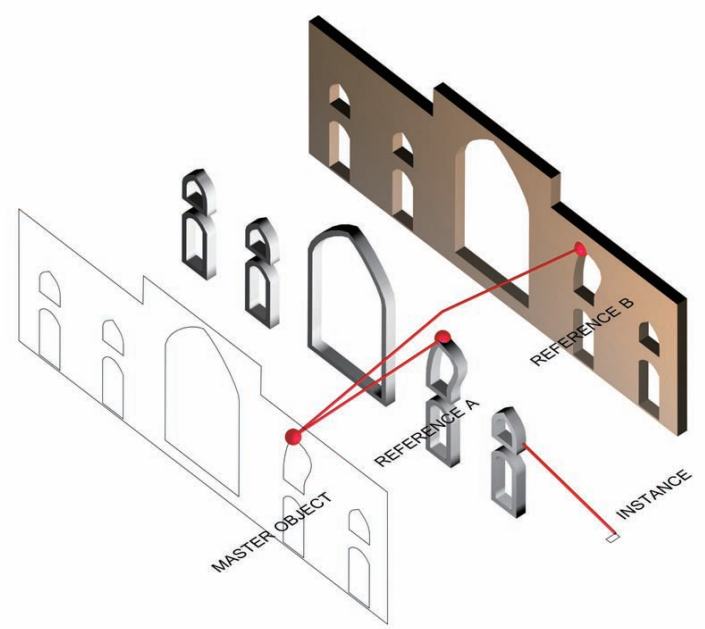

Fig. 48 First trial of 3-D modeling the small caravanserai and dependence reference of corresponding points.

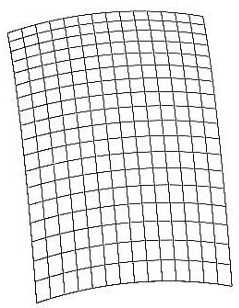

MESH

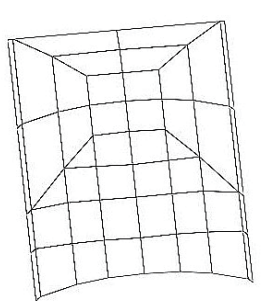

POLY

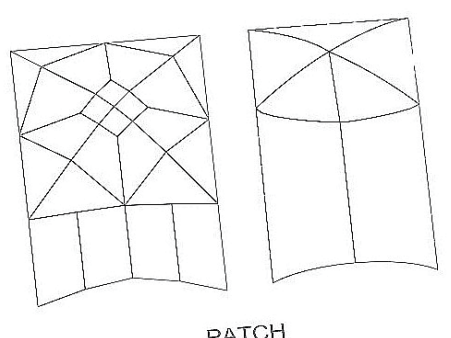

PATCH

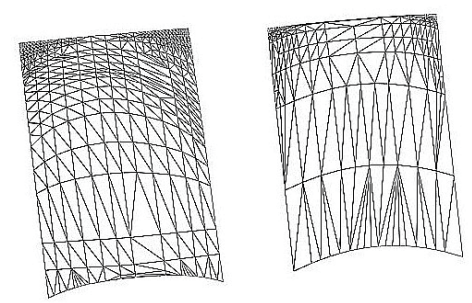

Surf NURBS

Fig. 49 Different methods of surface modeling (mesh, Poly, Patch, NURBS). 
nents of the model.

\section{Patch modeling}

Patch modeling and surface tools control curved and surfaces by using a minimum of points; the disadvantage is the lack of precise details; the drawings are more approximate than ones drawn geometrically, in particular, with respect to tangents. The patch technique is not suited to the varying level of detail in the survey on the two buildings. Moreover, as the complexity of the model increases, the modifications prove to be delicate and the dependences make the task difficult. Worse still, precision is lost when patches are converted into meshes and details are lost during optimization of the mesh after conversion (Fig. 50) [15].

\section{NURBS modeling}

The concept of dependence is inherent in NURBS. NURBS modeling seems to be more practical for deducing from the curves and existing surfaces and for keeping between them a link of dependence. However it is necessary to pass by splines for a correct geometrical construction for example when drawing arches. Splines can be converted into NURBS with good precision, but the need for rebuilding the NURBS curves to control the number of points slows down the modeling process. Moreover the topology of the mesh does not have the desired regularity when returning to the mesh model (Fig. 51) [16].

\section{Poly modeling}

Although modeling by polygon and the editing the mesh with all the editing tools is an artisan-like approach, it is nevertheless effective. Poly modeling allows a case-by-case approach, and each room of the buildings is different in its own way in order to answer all the surveyed geometries. However, the functionalities of these tools are not always compatible with the need for managing dependences. Each modification implies a new realization of the model (Fig. 52). This

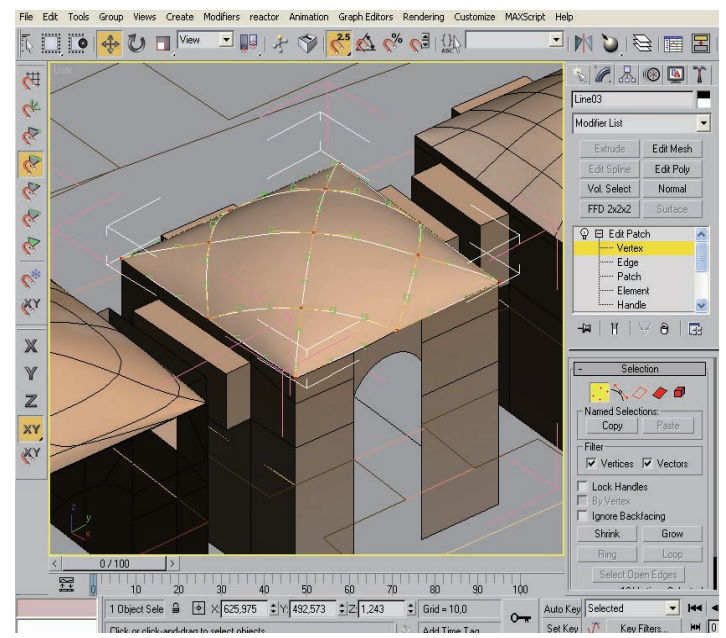

Fig. 50 Example of patch model of vault of a room in caravanserai 3-D model.

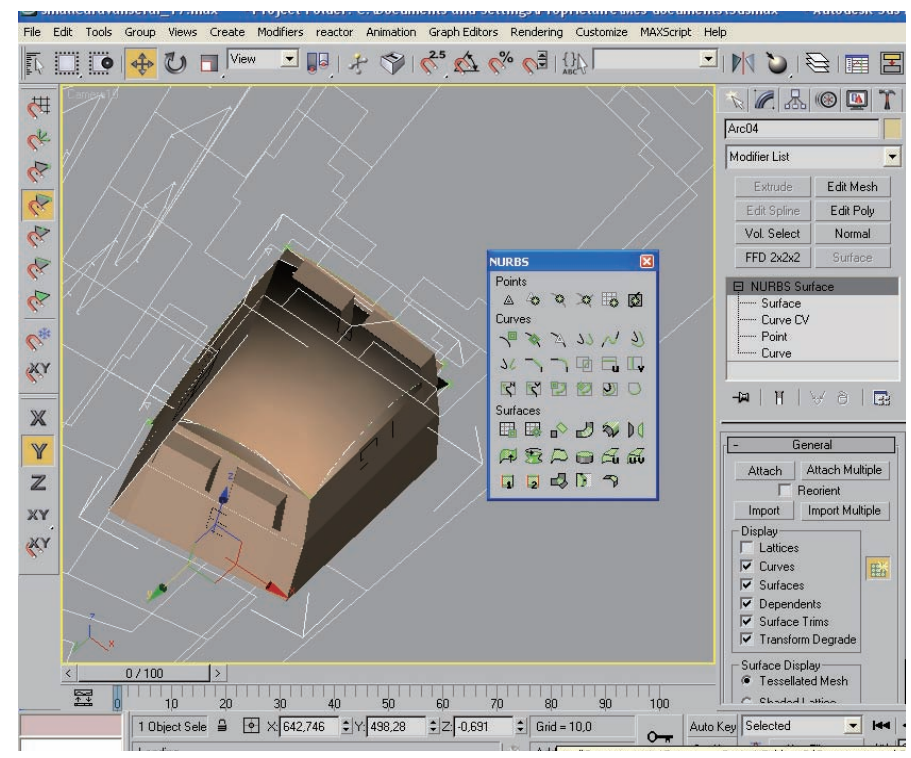

Fig. 51 Example of NURBS model of interior of vault of a room in caravanserai 3-D model. 


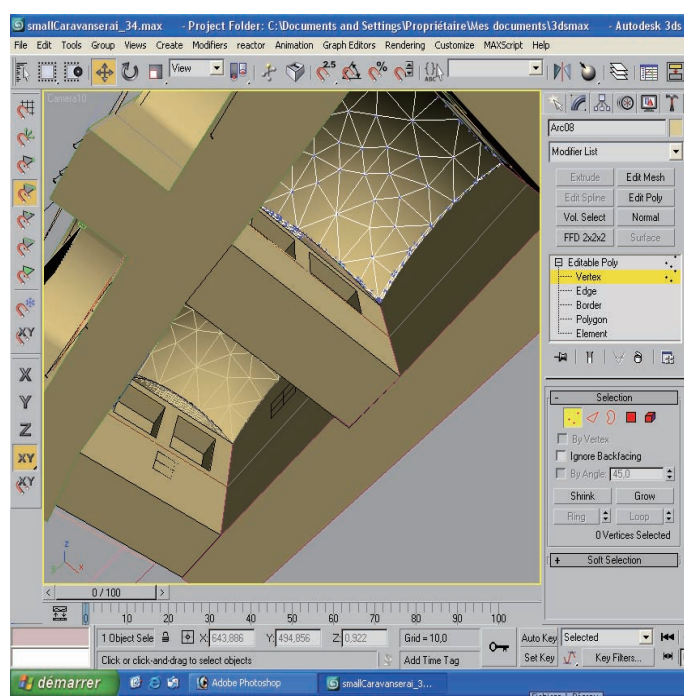

Fig. 52 Example of poly model (NURBS transform of polygons) of interior of vault of a room in caravanserai $3-D$ model.

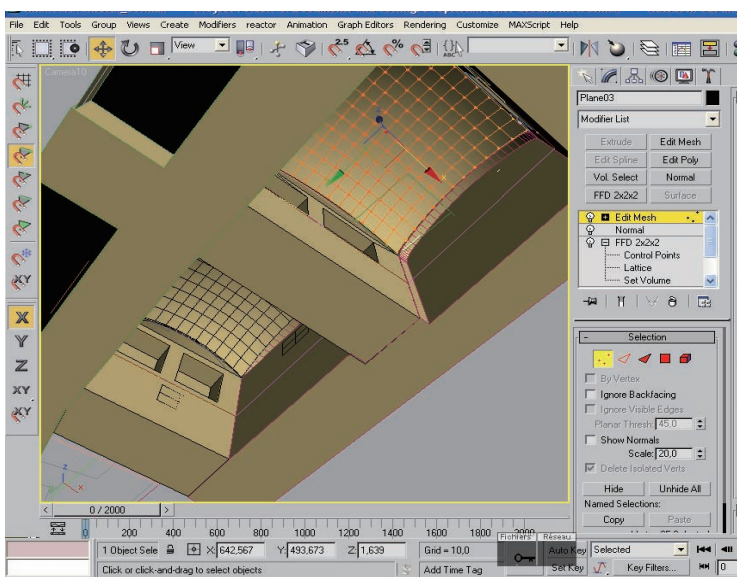

Fig. 53 Example of mesh model of interior of vault of a room in caravanserai 3-D model.

kind of modeling is like Japanese origami, which involves meticulousness and attention to details.

Fig. 53 shows a mesh modeling of a cloister vault (a mesh is simply a collection of vertices that define a 3-D object [17]), and Fig. 54 shows one for a ribbed vault.

\section{Technical evaluation and supervision of modifications}

The different teams developed 3-D models by using heterogeneous data such as maps, photos, and 3-D cartography map. The teams needed to take an analytic, comparative and semantic approach. The model-

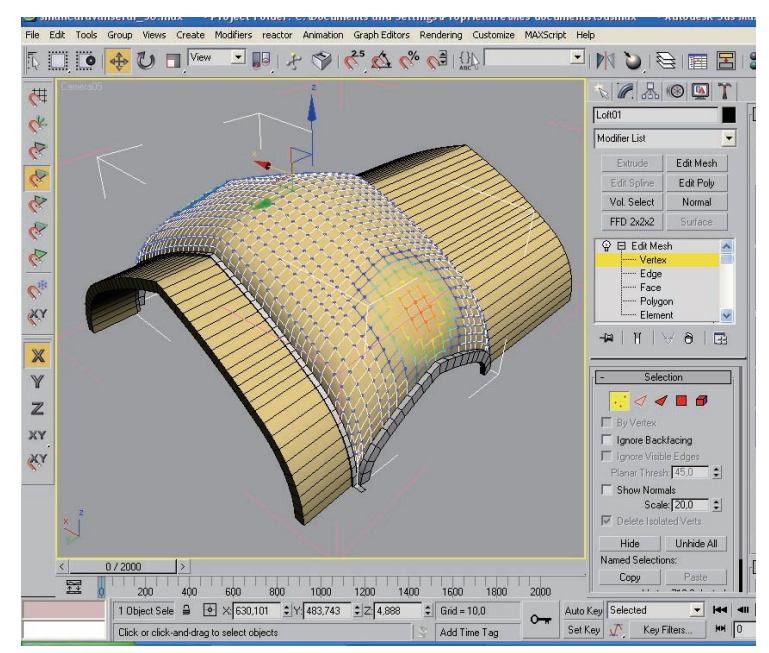

Fig. 54 Example of mesh model of a vault in caravanserai 3-D model.

ing process induced errors because the modelers were CG experts and not architects or historians. Therefore, the research team supported and supervised their output $^{40)}$. To assure the 3-D models' technical quality and their similarity to the real building, we undertook analytic and comparative research to establish a quality control process for the 3-D models and promptly reported errors to the modelers.

\subsection{Modifications}

The research involved architects who were experts on historical architecture and 3DCG experts. We evaluated the 3-D models against the available data resources (described in section 3 ) and told the team of developers about the errors. The errors reported were categorized as follows (see also Table 3 ).

Errors of architectural details and traditional methods

- Dimension errors in the superimposition of the models and 2-D maps (plans, facades, photos)

- Adjustment errors in the superimposition of the models on the 3-D cartography map

- Errors in architectural details that were revealed after comparing the models with photos taken before or after the earthquake. These included errors in the type of arch, drawings of vaults, missing details or elements such as windows or light holes, lintels, step, walls, and floors, errors in drawing

40) Technical control of 3-D models is done by Mr. Mohammad Reza Matini, Doctorate of Engineering and Dr. Elham Andaroodi, who evaluated the technical quality and architectural details of the 3-D models. 
the brick parapets and decorations such as chalk bands, etc.

\section{Layer naming and semantic errors}

- Errors in naming layers according to layer management guidelines, errors in prefix, infix, or suffix of the name string

- Errors in grouping components under a layer, such as grouping the top of a wall under the layer of roofs, etc.

\section{Technical 3D modeling errors}

- Errors in modeling showing for example, seams on what should appear to be solid pieces of wall, interference of different faces or solids, errors in drawing meshes especially of the interior vaults, and errors in Boolean functions for making volume sections, error of border between different architectural elements in the model.

After analysing the coincidence between 3-D models and the data resources on each building, the evaluators sent the developers modification reports indicating the errors in each part of the model and supervised the corrections. The developers are currently in the process of correcting and adjusting the 3-D models of first phase of Bam VR project.

This process involves step-by-step comparative 3-D modeling, and it requires precision and patience from everyone involved. Lack of primary references has made this process time consuming and complicated. The fact that the real heritage is seriously damaged added urgency to our task. Our 3-D model might be the only reference for a heritage may completely disappear from the real world. As an example the 3-D model of Sistani house was requested by a team of restorers in Bam as a reference for physical reconstruction ${ }^{41)}$ so precision of 3-D model was essential.

A comparison of the initial 3-D models and the final ones reveals considerable improvement in both the models and the modelers' skills.

\section{Construction of virtual reality space $^{42)}$}

The VR space of the completed 3DCG model is intended to be a basis for future restoration work. The OmegaSpace VR presentation software developed by Solidray Co., $\mathrm{Ltd}^{43)}$ was used to build the VR space.

41) A Dresden University team experienced in the restoration of traditional mud brick structures who is in charge of reconstruction of Sistani house under supervision of Prof. Wolfram Jäger and Dipl.-Ing. Christian. Fuchs.

42) This section is coauthored the same as section 6 .

${ }^{43)}$ http://www.solidray.co.jp/ [7 Jan, 2008].
OmegaSpace is also space construction software. It enables real-time rendering in a PC environment and it can be used in various fields. Moreover, it can be extended to a cyberspace type of system on a network whereby two or more users can use a single VR simultaneously. Thus, the VR space can be shared and cooperative work can be done in it. The process of preparing the VR of the simulations is shown in Fig. 55 the VR demonstration enables users to interact with the computer simulated spaces and walk virtually inside the buildings displayed on screen.

\subsection{VR preparation process}

Before importing the 3-D models to the VR tool, it was necessary to combine all the 3-D models into a unified environment. The basic map to superimpose the 3D model was 3-D cartography map imported to the tool and fitted to a black-and-white aerial photo taken after the earthquake. The 3-D models were attached to their positions by using the geographical features (longitude and latitude) of the 3-D cartography map of each building. The whole file was then exported to OmegaSpace. The layer management insured the least error during the process of merging the models.

The model was output in VRML form with coordinate information and read into OmegaSpace. The model could be lit arbitrarily, and two or more cameras were set up in each building. The walk-through could be done by switching cameras with a joystick. Moreover, we added a collision detection mechanism to prevent the operator from walking through walls and other objects in the model [18]. Images from the first trial VR demo of the citadel's main axes are shown in Fig. 56 and 57.

\subsection{VR demonstration}

OmegaSpace provides a viewing and interactive environment for 3-D and VR modeling. Nevertheless the complete application and virtual demonstration need specific demonstration technology. Three state-of-theart technologies that can be used for this purpose are:

- Cave: A virtual theater that includes a surroundscreen, surround-sound, projection-based virtual reality (VR) system ${ }^{44)}$.

- Responsive Workbench: a 3D interactive workspace. Computer-generated stereoscopic images are projected onto a horizontal tabletop display surface via a projector-and-mirrors system, and they are viewed through shutter glasses to generate the $3 \mathrm{D}$ effect ${ }^{45)}$.

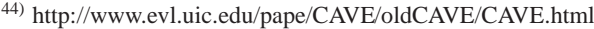

${ }^{45)} \mathrm{http}: / /$ graphics.stanford.edu/projects/RWB/
} 
Table 3 Evaluation of 3D models and proposed modification.

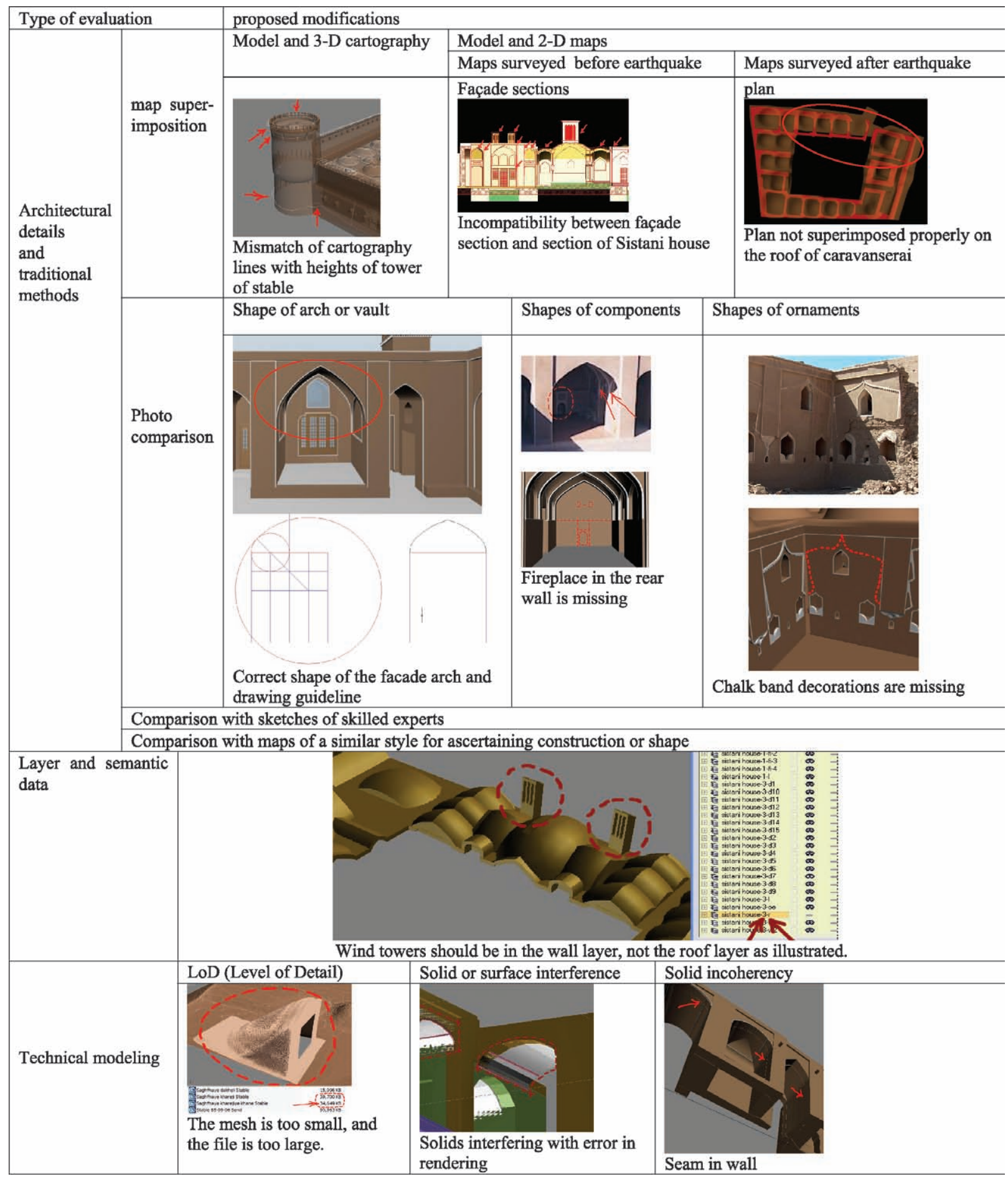




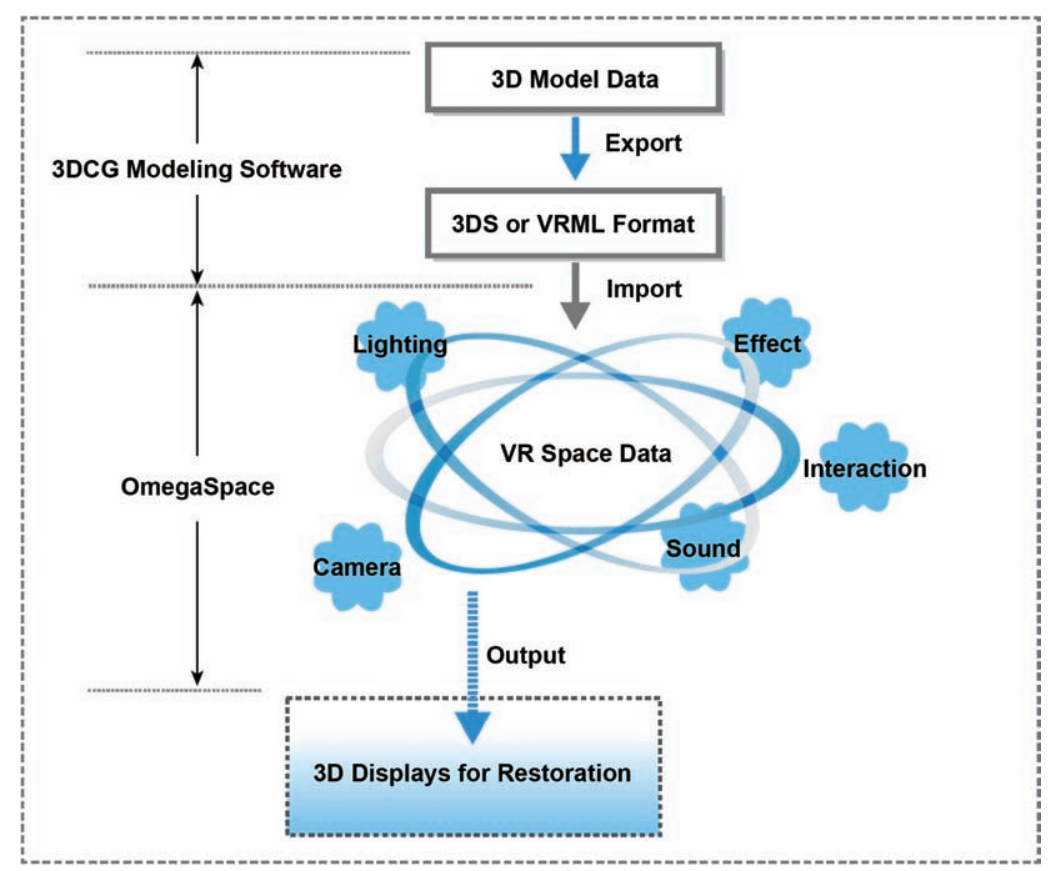

Fig. 55 VR workflow using OmegaSpace tool.

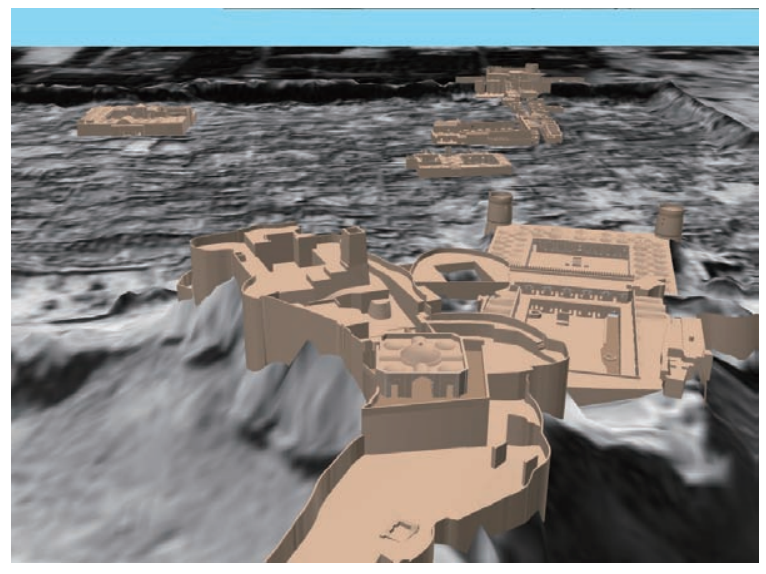

Fig. 56 Snapshot of VR scene from the top of citadel looking toward the city.

- 3D displays: any display device capable of conveying three-dimensional images to the viewer. Visbox or VisDuo ${ }^{46)}$ displays, planar SD stereo/3D monitors ${ }^{47)}$ and head mounted displays (HMD) such as 3DVisor ${ }^{48)}$ are examples of stereo-

\footnotetext{
46) http://www.visbox.com/stereo.html?gclid=CKGz1OmCx40CFRYYAod62oOGQ

47) http://www.sharpertechnology.com/planar.html/

${ }^{48)} \mathrm{http}: / /$ www.3dvisor.com/
}

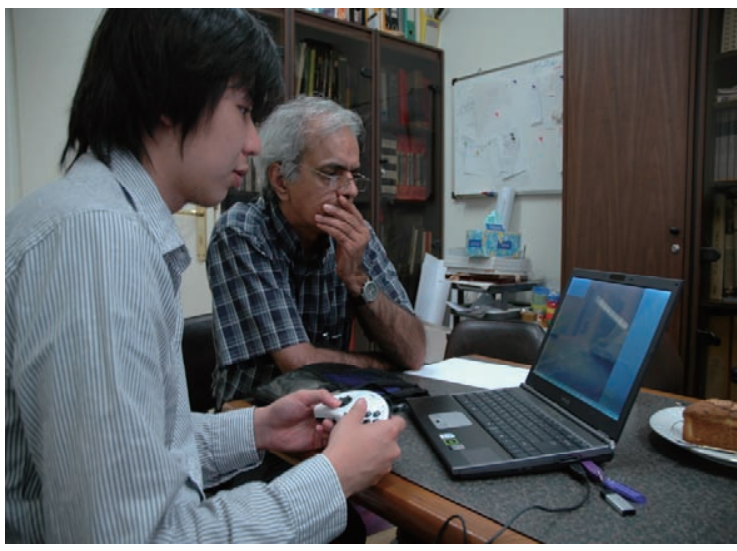

Fig. 57 First trial of VR demo of the Citadel of Bam.

scopic and autostereoscopic VR displays.

Each of these devices is defined inside the VR viewing and interactive freeware and can be used to create three dimensional images. The virtual reality demonstration of the VR theater in the Forbidden city of China is an example of an innovative application for revival and representation of a cultural heritage ${ }^{49)}$. We are currently testing the system that would be best for the Citadel of Bam VR demonstration.

49) $\mathrm{http} / / /$ www.barco.com/entertainment/en/references/references.asp?ref=2536 


\section{Conclusion and future perspectives}

This paper described collaborative research on developing a three-dimensional reconstitution and virtual reality of Bam and its cultural landscape, a UNESCO world heritage in danger. This research is now in the process of final modifications to the 3-D simulation of major buildings along the two main axes destroyed in the earthquake of 2003. These models were made as precisely as possible by using heterogeneous data (Fig. 56).

\subsection{Demonstrations}

The preliminary VR demonstration was presented in a workshop that was held at the Citadel of Bam in September 2006. The open house of NII in June 2007 also had a virtual tour inside the digitally restored citadel.

A virtual demonstration was broadcasted by NHK in its 'SOS from World Heritage' program in May $2006^{50)}$. In this program, the NHK Virtual Studio System [19] provided the virtual walk-through of the narrator inside the 3D simulation of the entrance and bazaar. The two models were separately loaded onto the virtual system in four sections to optimize the number of polygons as follows:

Entrance model (outside): 25517

Entrance model (inside): 20535

Bazaar model (inside): 11206

Bazaar model (aerial shot): 15992

Each of the sections became the background with a simple texture mapping, as shown in Fig. 58 and 59. As the narrator walked through, she explained the virtual restoration of the entrance and bazaar.

The latest demonstration of this project was provided by NHK at the anniversary of the earthquake in 26th December 200751). It was a short report in the news "good morning Japan" about latest achievement of modeling the 2 primary axes with walk through inside the 3-D model of Four Season building and the Sistani house.

The project was also introduced at, the Nihon Keizai Shimbun cultural section on December 21st 2004 ${ }^{52}$ and Mainichi Weekly on September 15th 2007 ${ }^{53)}$.

50) The program producers were:

Mr. Atsunori Kawamura - Executive Producer, Mr. Junichi Okamura - Executive Producer, Mr. Satoru Nagai - Senior Producer, Mr. Ryoichi Ogane Program Director/Producer.

51) Produced by Mr. Taro Mitamura, Science Reporter of the International Department of NHK.

52) Written by Mr. Masahiro Tamura, staff writer, cultural news department, editorial bureau, Nikkei shimbun.

53) Written by Ms. Akiko Ogawa from Mainichi Weekly, the Mainichi Newspapers.

\subsection{Main achievements}

The main achievements of our research till now are as follows:

- The CG simulation was done by simultaneously exploiting different data resources: 2-D maps, photos, cartography maps, movie, sketches of experts, etc. were used together to complete the model.

- The research to determine the original shapes of destroyed buildings aided the 3-D modeling team in increasing the model's precision.

- 3-D modelers, architects, historians, and CG experts worked closely together to create the output.

- Application of layer management added semantic (type of building, type of resource, type of component) to 3-D models.

- Remodeling and technical evaluations enhanced the technical quality of the output to be used as accurate digital documentation even for physical restoration.

- Scientific exchange between students, researchers, and professors from different nationalities enhanced their level of knowledge of CG modeling and historical architecture. This research provided them with knowledge and experience they can use for 3-D documentation of similar architectural heritages made from mud.

- The task of managing a large modeling process illustrated differences in the modelers' approaches toward 3DCG.

- The VR demonstration revived buildings of the Citadel of Bam which are now impossible to visit in the real world.

\subsection{Future tasks}

We will complete the 3-D modeling, and will provide rendering and texturing of the buildings to give realistic views. and will devise a semantic VR demonstration with accompanied metadata such as textual or visual annotations. Moreover, a survey on the site to determine the next case studies for modeling will be necessary. The potential survey locations are shown in Fig. 60.

The following tasks are involved in the second stage of modeling:

- Model case studies of important buildings including the governor's house, commander's house, the 


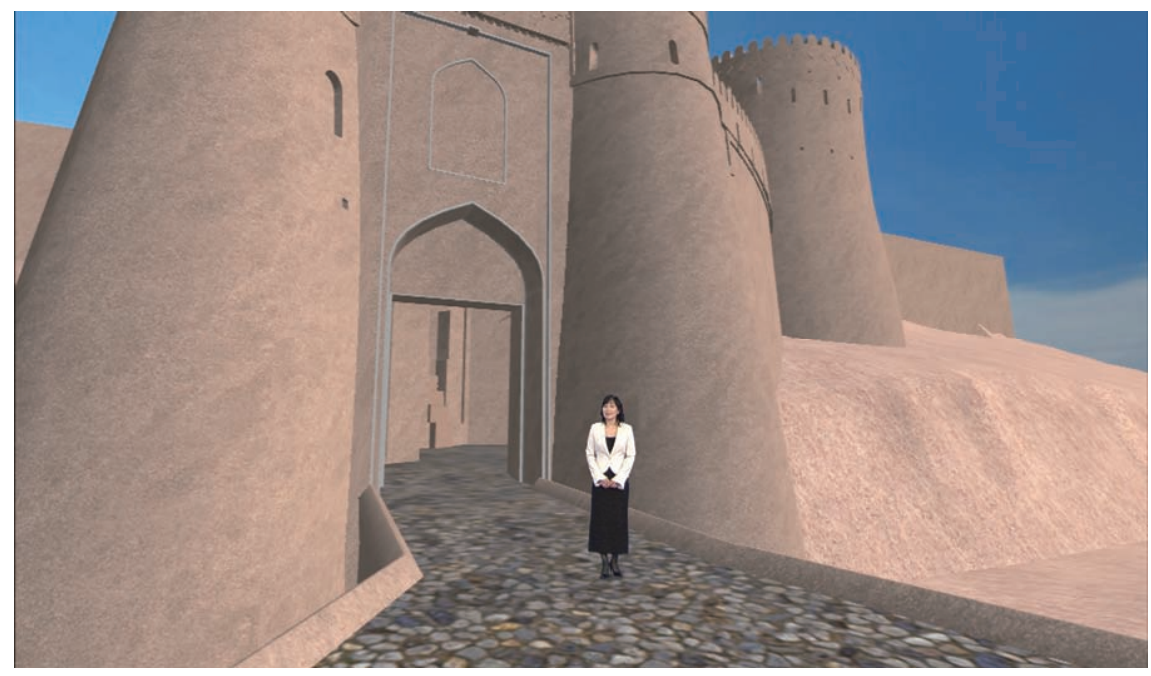

Fig. 58 Entrance (main gate) of the citadel and virtual narrator, photo courtesy of NHK.

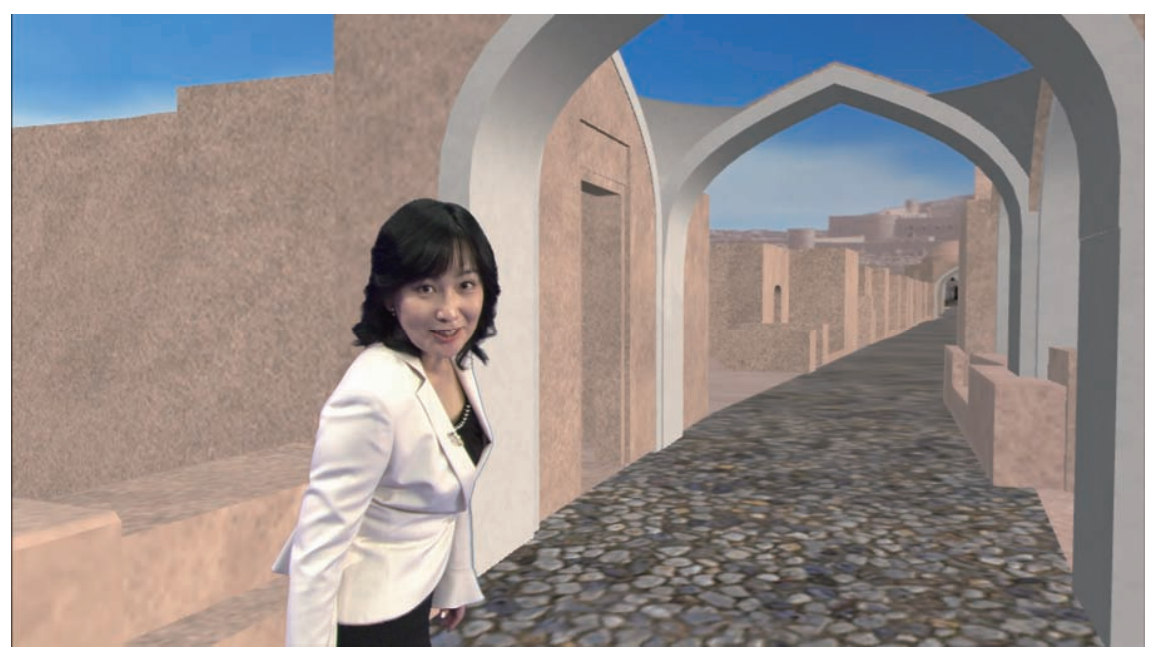

Fig. 59 Virtual walk inside bazaar, photo courtesy of NHK.

second, third, fourth and ancient gates, the surrounding and defensive walls, and slopes and other topography (as specified in Fig. 60).

- Develop a multilingual and metadata-based knowledge model proper for annotation of the 3-D building models

- Do analytic and comparative research on the vague parts of the Citadel of Bam, the ordinary people's residences, and make a simple simulation of these districts (red parts of Fig. 60).

- Properly render and texture the developed 3-D models
- Prepare a new VR demonstration

\subsection{Proposal for future modeling process}

As a solution to increase the technical quality and correctness of the 3-D models, to reduce the number of errors in 3-D models, and to make the process of modeling faster and avoid remodeling, we propose that a semantic wire-frame 3-D simulation complementary exploiting heterogonous data resources be used by the 3-D model developers as their main reference. The research plan is illustrated in Fig. 61. 

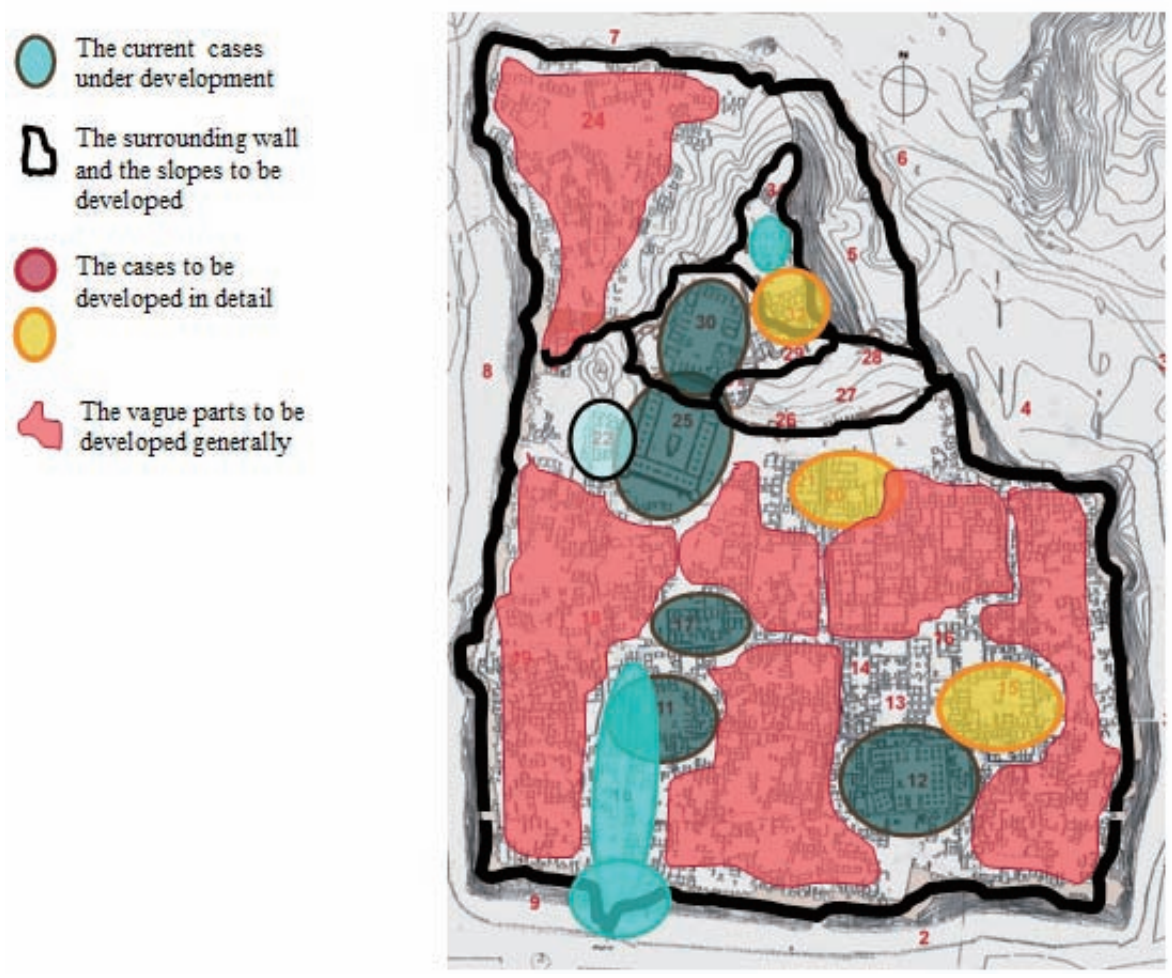

Fig. 60 Proposal for future 3-D modeling on the site plan.

11.5 Proposal for open access to Internet data

Currently, a report on the VR of the Citadel of Bam is accessible at the DSR project website of NII ${ }^{54)}$. The following is proposed for the future demonstration of the 3-D model and the virtual reality demonstration as part of the Digital Silk Roads [20].

- Interactive map and photos from the 3-D models

- MPEG format walk-through of the 3-D models

- QuickTime virtual reality demo of the 3-D models

Furthermore, an ontology knowledge model will be developed to provide a Topic Map application on the Internet and link different types of resources and the 3$\mathrm{D}$ models with its metadata and related topics such as typology.

This work is a practical contribution related to the subjects of digital archives and 3DCG on solving the problems affecting the revival of a real-world heritage damaged in a natural disaster.

\section{Acknowledgements}

The authors would like to express their sincere gratitude to Prof. Masao Sakauchi (Director General of NII)

\footnotetext{
54) http://dsr.nii.ac.jp/bam/virtual/Bam-VR-report-V3.pdf [7 Jan 2008].
}

and Prof. Yohichi Tohkura (Deputy Director General of NII) for supporting Bam 3DCG Virtual reconstitution project. In addition, we greatly appreciate the cooperation and support of the Iranian Cultural Heritage and Tourism Organization (ICHTO), Dr. Hossein Tayyari (previous head of the Bam restoration project), Dr. Mahmoud Nejati (Deputy of Research \& Technical Consultant, Recovery Project of Bam's Cultural Heritage), Ms. Mahshid Jafarizadeh (expert of Recovery Project of Bam's Cultural Heritage), Ms. Mahsa Momenzadeh (Recovery Project of Bam's Cultural Heritage), Mr. Akbar Taghizadeh (head of the Pardisan project), and Ms. Fariba Farzam (head of ICHTO Documentation Centre). We would like to appreciate too Ms. Fatemeh Farahani (head of cultural sector of the Iranian National Commission of UNESCO) for her support.

We also appreciate former Director General of NII Prof. Yasuharu Suematsu, Prof. Emeritus Takeo Yamamoto and members of the Digital Silk Road project, Prof. Yoshiyori Urano (GITI, Waseda University), Assoc. Prof. Fredric Andres (NII), Prof. Pierre Lebigre (EVCAU), and Prof. André Del (EVCAU).

We would like to thank other contributors who provided us with photos, movies and documents related 

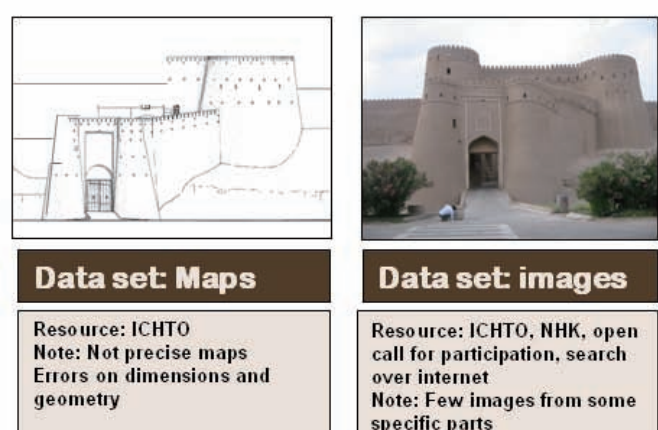

Data set images

Reso urce: ICHTO, NHK, open call for participation, search over internet Note: Few images from som specific part

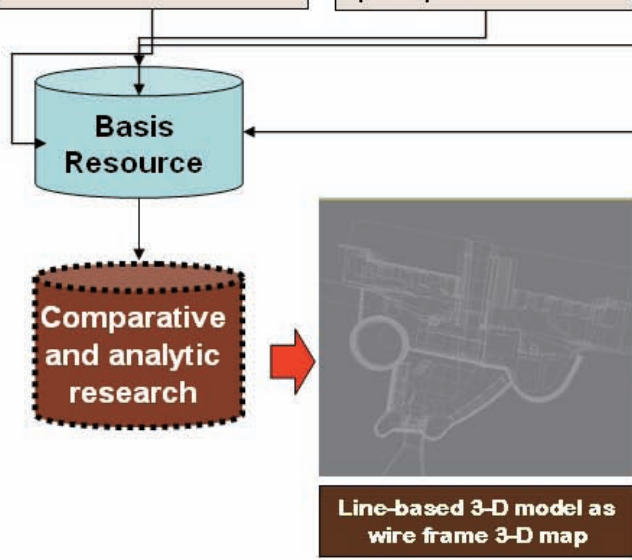

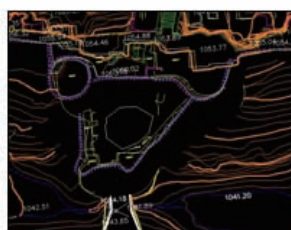

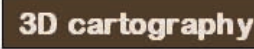

Resource: IFCA Note: it is only lines not a surface.

The 3-D of vertical faces are The $3-D$ of vertical faces available or very few
not

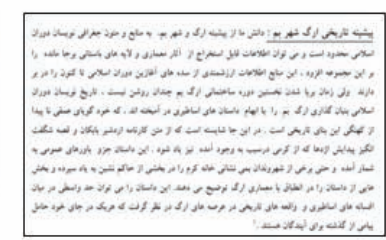

\section{Data set: text}

Resource: ICHTO, experts who remembered the building Note: in some cases this was the only resource for 3-D modeling

Fig. 61 Process of analytic and comparative research on available data resources for development of a line-based 3-D model as a wire-frame-map basic modeling resource.

to Bam especially Mr. Ryoichi Ogane (NHK) and Ms. Atsuko Tai (NHK) and Ms. Chihiro Ohkubo. Special thanks to team of modelers Mr. Human Kian-Ersi, Mr. Pouya Khosro Jerdi, and Mr. Morteza Hengofti, Mr. Ha Young Yoon, Ms. Vida Gholipour Mr. Benoit Guillou, Ms. Sahar Ghaderi and Mr. Majid Bequali.

This work is partially supported by Grants-in-Aid for Scientific Research (Category A: Principal Investigator Kinji Ono) by JSPS.

\section{References}

[1] M. Mehriar, "the history of Citadel of Bam", Published report of archaeological studies (in Persian), Bam recovery office, Iranian Cultural Heritage and Tourism Organization, 2004.

[2] A. Karimi, The architecture of Citadel of Bam and the Silk industry, Proc. the second congress of the history of Iranian architecture and urbanism, Iranian Cultural Heritage Organization, 2001, pp. 233, 267. (in Persian)

[3] H. Tayyari, "The report of the results of the project of Citadel of Bam from 1372 (1993) till 1374 (1995)," Proc, the congress of the history of Iranian architecture and urbanism, Fifth Volume, Iranian Cultural Heritage
Organization, 1997, pp.11-21. (in Persian)

[4] A. Ibn e Haugal, Surat-ol-Arz, Translated by J. Sho'aar, 1345, Tehran. (in Persian)

[5] A. Gruen, F. Remondino, and L. Zhang, "Image-based Reconstruction and Modeling of the Great Buddha Statue in Bamiyan, Afghanistan, International Archives of the Photogrammetry," Remote Sensing and Spatial Information Sciences, Vol.XXXIV-5/W10.

[6] D. Miyazaki, T. Ooishian, T. Nishikawa, R. Sagawa, K. Nishino, T. Tomomatsu, Y. Takase, and K. Ikeuchi, "The Great Buddha Project: Modeling Cultural Heritage Through Observation," Proc. 6th Int. Conf. Virtual Systems and MultiMedia (VSMM 2000), Dec. 2000, pp.138-145, 2000

[7] J. Stumpfel, C. Tchou, and N. Yun et al. "Digital Reunification of the Parthenon and its Sculptures," 4th International Symposium on Virtual Reality, Archaeology and Intelligent Cultural Heritage, 2003.

[8] J. Jacobson and J. Vadnal, "The Virtual Pompeii Project," Proceedings of World Conference on ELearning in Corporate, Government, Healthcare, and Higher Education, 2005. 
[9] C. Ioannidis, C. Potsiou, and J. Badekas, “3D Detailed Reconstruction of a Demolished Building by Using Old Photographs," International Archives of Photogrammetry and Remote Sensing, Vol. XXXI, Part B5, Vienna 1996.

[10] K. Hanke and P. Grussenmeyer, "Architectural Photogrammetry: Basic Theory," Procedures, Tools, Corfu, ISPRS Commission, 5 tutorials, September 2002.

[11] B. Fleming, 3D modeling and Surfacing, Eslevier, 1999.

[12] A. H. Watt, 3D Computer Graphics, ADDISON WESLEY, Third edition, 2000.

[13] K. Haji-Qassemi, ed. Ganjnameh: Cyclopedia of Iranian Islamic Architecture, (Vol., 3), Tehran: Cultural Heritage Organization and Shahid Beheshti University, 1998. (in Persian)

[14] M. Raees-Zadeh and H. Mofid, Restoring Forgotten Arts: Fundamentals of Iranian Traditional Architecture Based on Hossain Lorzadeh Naration, Tehran: Moola Press, 1996. (in Persian)

[15] Introduction to Patch modeling www.mathworks.com/ access/helpdesk/help/techdoc/visualizelf2-31825.html [7 Jan 2008]. http://www.geocities.com/hamatut/help/ intro.html [7 Jan 2008]. http://movielibrary.lynda.com/ html/modPage.asp?ID=112 [7 Jan 2008].

[16] D.F. Rogers, An Introduction to NURBS Modeling, with Historical Perspective, Academic press, 2001.

[17] Introduction to Polygonal Modeling http://www.oman3d.com/tutorials/3ds/polymod_stealth/ [7 Jan 2008]. http://movielibrary.lynda.com/html/ modPage.asp?ID=112 [7 Jan 2008]. http://caad.arch. ethz.ch/info/maya/manual/UserGuide/ModelingPoly/ PolyIntro.fm.html [7 Jan 2008].

[18] E. Andaroodi, M. Matini, N. Abe, K. Ono, T. Kawai, "3-D Reconstitution and Virtual Reality of the World heritage in Danger, Citadel of Bam," Proc. of the Virtual Environments 2007,13th Eurographics Symposium on Virtual Environments Editor: Dieter Fellner, ISBN 978-3-905673-64-7 (Eurographics).

[19] T. Kurosaki, T. Inoue, N. Kasaba, S. Wakamatsu, K. Makino, K. Ozeki, N. Yamada, "2-2 Broadcasting Facilities and Operations," The journal of the Institute of Image Information and Television Engineers, vol.52, no.8, pp.1107-1115, 1998.

[20] K. Ono, T. Yamamoto, T. Kamiuchi, A. Kitamoto, F. Andres, S. Sato, E. Andaroodi "Progress of the Digital Silk Roads project," Prog. in Informatics, no.1, pp.93141,2005

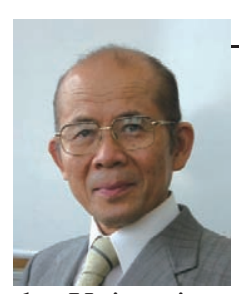

Kinji ONO

Kinji ONO is a professor emeritus and special appointment professor for Digital Silk Road project at National Institute of Informatics (NII) and visiting professor of Waseda University. He received his B.S. in physics from the University of Tokyo, M.Sc in electrical engineering from Stanford University, and Dr. of engineering from the University of Tokyo. After serving as director of the Research Laboratories of KDD, he became professor and director of R\&D at NACSIS in 1993. After NACSIS was reorganized into NII in April 2000, he served as professor and executive director for research until March 2004. His research interests cover computer communications, network architecture and protocol, distributed multimedia, digital archives of cultural heritage. He served as vice chairman of TSAG of ITU, program chairman of ICCC '99, chairman of Information Access of CULCON, co-executive director for the Digital Silk Roads Initiative Framework (DSRIF) of UNESCO, and chairman of the Tokyo and Nara Symposium of Digital Silk Roads. He received the Purple Ribbon Medal in 2002. He is a Life Fellow of the IEEE and a Fellow of the IEICE and IPSJ.

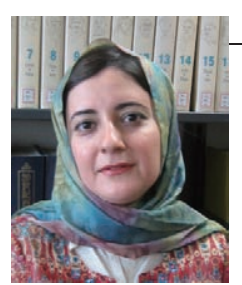

\section{Elham ANDAROODI}

Elham ANDAROODI is a postdoctoral researcher of the Digital Silk Road project of the National Institute of Informatics (NII). She earned her master's degree in architectural engineering from the University of Tehran in 2001 and got her Ph.D. from NII and the Graduate University for Advanced Studies in 2006. She has been an expert of the Iranian Cultural Heritage Organization and had renovated Ameri-Arsham historical houses in Bam (Iran) from 2001 to 2002.

Her research interest is knowledge management for cultural heritages, the classification of architectural edifices, their spatial analysis and 3-D simulation. She has received award of cultural research of the year 2001, from the Ministry of Culture and Islamic Guidance, and the Young Khwarazmi award of the year 2002, from the Ministry of Science, Research and Technology for her research on caravanserais of the Silk Roads in Iran. 


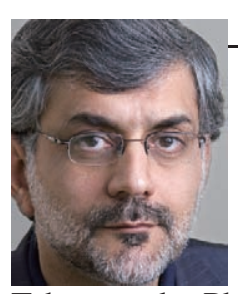

\section{Alireza EINIFAR}

Alireza EINIFAR is an associate professor of architecture in the Faculty of Architecture, University College of Fine Arts, University of Tehran. He received a master's degree in architecture from the University of Tehran and a Ph.D. in the same field from the University of New South Wales, Sydney, Australia. After serving as head of the School of Architecture, University of Tehran from 1997 to 2000, he was Director of Postgraduate Studies at the Faculty of Fine Arts from 2000 to 2005. After an administrative change of faculties to the University College at the University of Tehran, he now serves as vice chancellor for Planning and Development at the University College of Fine Arts. His major area of research is the history and theory of architecture, and his special interests are cultural landscape and environmental studies.

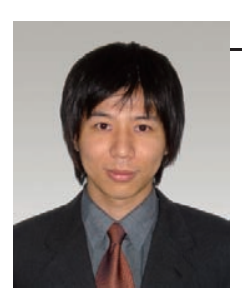

Nobuaki ABE

Nobuaki ABE is currently enrolled in the doctoral program at the Graduate School of Global Information and Telecommunication Studies at Waseda University. He received his B.A. degree in arts in performance, and M.S. degree in global information and telecommunication from Waseda University, in 2004 and 2006, respectively. His research interests include 3-D CG, digital archives, and virtual reality.

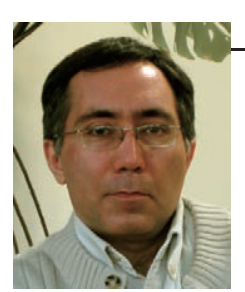

Mohammad Reza MATINI

Mohammad Reza MATINI received his master's degree in architectural engineering from the Faculty of Fine Arts, University of Tehran, in 1998. He worked for five years in architecture offices as designer in Tehran and Mashhad and was a lecturer of architecture at Azad University of Mashhad from 1998 to 2003. He received his doctor of engineering degree from the Faculty of Architecture, University of Stuttgart in 2007.

His major interest is the development process of architectural designs based on geometrical patterns and implementation of computer aided design as a tool to facilitate the formation process. He used this method to transform natural principles into convertible structures in architecture in his doctoral thesis. He is currently a post-doctoral researcher at National Institute of Informatics.

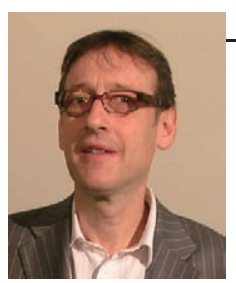

Olivier BOUET

Olivier BOUET is an associate professor at the Ecole Nationale Supérieure d'Architecture de Paris Val de Seine (ENSAPVS). He received B.S. and M.S. in physics from the University of Paris XI and his Dr. of optics and image processing from the University of Paris VI. He has worked on medical image processing in the GAIB laboratory (University of Paris VI) and on archeological restitution and virtual reality at the Espace Virtuel pour la Conception Architecturale et Urbaine lab (EVCAU).

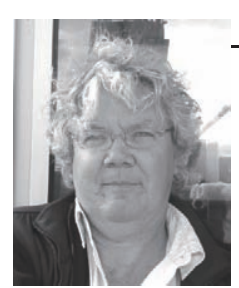

\section{Frank CHOPIN}

Frank CHOPIN is DPLG architect, lecturer and researcher of the Espace Virtuel pour la Conception Architecturale et Urbaine (EVCAU), a laboratory of the Ecole Nationale Supérieure d'Architecture de Paris Val de Seine (ENSAPVS). He made research on picture synthesis in the research structures (Ecole des Mines de Saint-Etienne) before the software became commercial. During the 1990s, he worked for Ikone Infographie Corporation, one of the pioneers of picture synthesis for architectural offices. He is responsible for courses on computer graphics at architecture schools since 1991. 


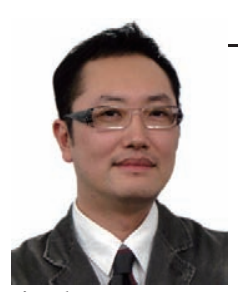

Takashi KAWAI

Takashi KAWAI graduated from the School of Human Sciences, Waseda University in 1993. He received his B.A., M.A., and Ph.D. degrees in human sciences from Waseda University in 1993, 1995, and 1998, respectively.

He became a research associate at the School of Human Sciences, Waseda University in 1998 and an assistant professor at the Global Information and Telecommunication Institute, Waseda University in 2000. He has been an associate professor at the Graduate School of Global Information and Telecommunication Studies, Waseda University since 2002.

His recent research interests are the application and evaluation of advanced media technologies from the viewpoint of human factors.

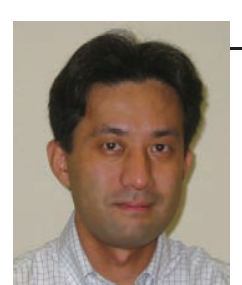

\section{Asanobu KITAMOTO}

Asanobu KITAMOTO is an associate professor of the Digital Content and Media Sciences Research Division, National Institute of Informatics (NII). He received his B.S., M.S. and $\mathrm{Ph} . \mathrm{D}$. in electronic engineering from the University of Tokyo. He joined NACSIS in 1997 as a research associate and has been an associate professor at NII since 2004. His research focuses on the application of data-centric approaches to various academic domains, including earth science (e.g., meteorological databases) and humanities (e.g., cultural digital archives).

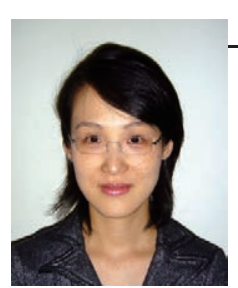

\section{Asaka ITO}

Asaka ITO graduated from the School of Human Sciences, Waseda University in 1997. She received her B.A. degree in human sciences from Waseda University in 1997.

After working on the space design of office spaces as an interior coordinator, she started creating 3D images and editing movies on architecture and medicine. She started her own company, Ergovisions, in 2005.

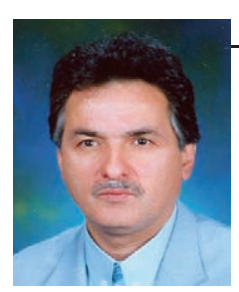

\section{Eskandar MOKHTARI}

Eskandar MOKHTARI is graduated from Tehran University with a degree in archaeology and art history and did his postgraduate studies at Pardis University on the restoration of monuments and historical fabrics. He holds a Ph.D. in art research from Azad University. His research and maintenance projects have included over 170 historic properties in Saveh, Tehran, and Bam. His studies have ranged from rudiments of Islamic architecture in Iranian penmanship in the field of contemporary architecture to pedagogy at universities and higher education institutions in the fields of architecture, preservation, and restoration of historical edifices.

From 1994 to 2004, he was deputy-president of the Department of Preservation and Rehabilitation of Historical Monuments of the Tehran Cultural Heritage Organization. Following the Bam earthquake in 2003, he became director of Recovery Project of Bam's Cultural Heritage.

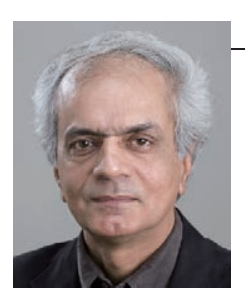

\section{Saeed EINIFAR}

Saeed EINIFAR is a professional architect and director manager of Razahang Architectural Consultants in Tehran, Iran. He received his M. Arch degree from the University of Tehran in 1981. He is a specialist in computer graphics and an experienced photographer. He served as lecturer in photography from 1984 to 1989 in the Faculty of Fine Arts, University of Tehran. During last two decades, his professional activity has concentrated on architectural design and practice. One of his major designed and constructed buildings is the Ministry of Energy Headquarters in Tehran (completed in 2005). 


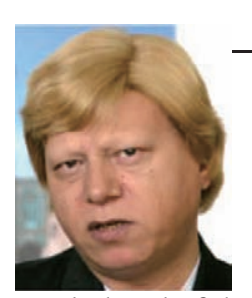

Seyyed Mohammad BEHESHTI Seyyed Mohammad BEHESHTI was deputy minister and head of the Iranian Cultural Heritage Organization(ICHO) from 1997 to 2005. He was head of the Farabi Film Foundation in Iran in the 1990s. He is currently head of the Architecture and Urban Planning Department of the Iranian Academy of the Arts and head of the Electronic Encyclopedia of Iranian Architectural History. He is member of the supervisors of 3DCG virtual reconstitution of UNESCO world heritage in danger, Bam and its Cultural Landscape. He received his master's degree on architectural engineering from the University of Shahid Beheshti in Tehran.

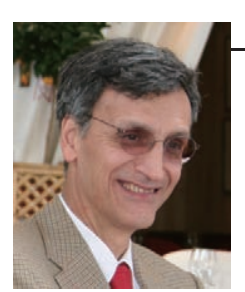

\section{Chahryar ADLE}

Chahryar ADLE is currently research director at the French National Centre for Scientific Research (CNRS). He studied oriental archaeology and the arts of Islam at the Ecole du Louvre (Louvre Museum, Paris), and presented his memoir to the Fourth Section of the Ecole Pratique des Hautes Etudes (EPHE, Sorbonne, Paris). He obtained his $\mathrm{Ph}$. D. from the University Sorbonne Nouvelle in Paris in 1976. Doctor Adle is a member of the editorial board of the Studia Iranica and leads archaeological investigations in Iran and the IranoAfghan Border. $\mathrm{He}$ is the president of the International Scientific Committee for the Publication of the History of Civilizations of Central Asia (published by UNESCO). He has been awarded the CNRS Bronze Medal for Research (France, 1985) for his archaeological discoveries in Bastam and UNESCO's Aristotle Silver Medal (1996) and Avicenna's Medal for his contributions on the subject of Central Asian civilizations. After the earthquake which devastated the region of Bam (Iran) on 26 December 2003, he took charge of the Franco-Iranian project on investigating and 3D mapping of the archaeological remains in that area. 